\title{
Administration of follicle-stimulating hormone induces autophagy via upregulation of HIF-1a in mouse granulosa cells
}

\author{
Jilong Zhou ${ }^{1}$, Wang Yao ${ }^{1}$, Chengyu Li ${ }^{1}$, Wangjun Wu ${ }^{1}$, Qifa Li ${ }^{1}$ and Honglin Liu ${ }^{\star, 1}$
}

Recent studies reported the important role of autophagy in follicular development. However, the underlying molecular mechanisms remain elusive. In this study, we investigated the effect of follicle-stimulating hormone (FSH) on mouse granulosa cells (MGCs). Results indicated that autophagy was induced by FSH, which is known to be the dominant hormone regulating follicular development and granulosa cell (GC) proliferation. The activation of mammalian target of rapamycin (mTOR), a master regulator of autophagy, was inhibited during the process of MGC autophagy. Moreover, MHY1485 (an agonist of mTOR) significantly suppressed autophagy signaling by activating mTOR. The expression of hypoxia-inducible factor 1 -alpha (HIF-1 $\alpha$ ) was increased after FSH treatment. Blocking hypoxia-inducible factor 1-alpha attenuated autophagy signaling. In vitro, $\mathrm{CoCl}_{2}$-induced hypoxia enhanced cell autophagy and affected the expression of beclin1 and BCL2/adenovirus E1B interacting protein 3 (Bnip3) in the presence of FSH. Knockdown of beclin1 and Bnip3 suppressed autophagy signaling in MGCs. Furthermore, our in vivo study demonstrated that the FSH-induced increase in weight was significantly reduced after effectively inhibiting autophagy with chloroquine, which was correlated with incomplete mitophagy process through the PINK1-Parkin pathway, delayed cell cycle, and reduced cell proliferation rate. In addition, chloroquine treatment decreased inhibin alpha subunit, but enhanced the expression of 3 beta-hydroxysteroid dehydrogenase. Blocking autophagy resulted in a significantly lower percentage of antral and preovulatory follicles after FSH stimulation. In conclusion, our results indicate that FSH induces autophagy signaling in MGCs via HIF-1 $\alpha$. In addition, our results provide evidence that autophagy induced by FSH is related to follicle development and atresia.

Cell Death and Disease (2017) 8, e3001; doi:10.1038/cddis.2017.371; published online 17 August 2017

Macroautophagy (hereafter referred to as autophagy) is a constitutive, dynamic, evolutionarily conserved catabolic process that involves the degradation and recycling of cellular constituents. ${ }^{1,2}$ It maintains cell survival under various forms of stress conditions such as starvation, ${ }^{3}$ hypoxia, ${ }^{4}$ and interruption of growth signaling. ${ }^{5}$ Autophagy is involved in many physiological and developmental processes such as cell survival, cell death, metabolism, and innate immunity. ${ }^{6-8}$ Abnormalities in autophagy are implicated in numerous human diseases, including developmental disorders, neurodegenerative diseases, and cancer. ${ }^{9}$

A granulosa cell or follicular cell is a somatic cell of the sex cord that is closely associated with the developing female gamete (called an oocyte or egg) in the mammalian ovary. Ovarian follicle atresia is a periodic process by which immature ovarian follicles degenerate and are reabsorbed during the follicular phase of the ovarian cycle. This complicated, dynamic process is triggered by GC apoptosis. ${ }^{10,11}$ Recently, increasing evidence shows that autophagy plays a vital role in survival and proliferation of GCs. ${ }^{12,13}$ In rat GCs, accumulation of autophagosomes induced by serum starvation activates cell apoptosis through decreased Bcl-2 expression and, subsequently, leads to caspase activation, ${ }^{14}$ which suggests that a certain degree of autophagy may promote GC apoptosis. In a mouse model, inhibition of autophagy in IL-33
(-/-) mice leads to massive accumulation of tissue waste containing aging-related catabolic waste during folliculogenesis, indicating a role for autophagy in removing unnecessary cells and maintaining the metabolic balance in antral follicles. ${ }^{15}$ Interestingly, specific knockout of autophagyrelated genes results in a significant decrease in primordial follicle pools, ${ }^{16,17}$ which suggests an important role for autophagy in the regulation of follicular development and maintenance of the ovarian primordial follicle reserve.

Factors related to follicular development and GC proliferation have been extensively investigated, including death ligands and receptors, caspases, Bcl-2 family members, and gonadotropins. ${ }^{18}$ Follicle-stimulating hormone $(\mathrm{FSH})$ is synthesized and secreted by the gonadotropic cells of the anterior pituitary gland and plays an important role in follicular development, GC proliferation, and reproductive processes. Exogenous $\mathrm{FSH}$ is widely used to stimulate the development of mature follicles because of its effectiveness in preventing GC apoptosis and follicle atresia. Research indicated that almost all gonadotropins can significantly inhibit GC apoptosis and follicle atresia, with FSH exhibiting the highest efficiency. ${ }^{19,20}$ Exposing immature rats to eCG can significantly decreased autophagy signaling at days 1 and 2, but increased it at day 3 and maintained it until day $5,{ }^{21}$ suggesting a complex regulation of autophagy during follicular

${ }^{1}$ College of Animal Science and Technology, Nanjing Agricultural University, Nanjing 210095, China

*Corresponding author: H Liu, College of Animal Science and Technology, Nanjing Agricultural University, Nanjing 210095, China. Fax: +025 84399762 ; E-mail: liuhonglin@njau.edu.cn

Received 03.3.17; revised 25.6.17; accepted 04.7.17; Edited by M Piacentini 
development. However, the relationship between autophagy and inhibition of cell apoptosis and follicle atresia by FSH remains unclear. In this study, we investigated the molecular regulation of autophagy in FSH-treated MGCs to determine the role of FSH in GC autophagy and apoptosis.

\section{Results}

FSH promotes MGC autophagy in vivo. To determine whether the function of FSH is correlated with autophagy in MGCs, we measured autophagy signaling during $48 \mathrm{~h}$ after FSH treatment in vivo. Immunohistochemical analysis indicated that FSH injection increased endogenous LC3 expression when compared with the control group ( $0 \mathrm{~h}$; Figure 1a). In particular, LC3-positive staining was concentrated in the MGCs of antral and preovulatory follicles, both $\mathrm{FSH}$-sensitive follicles. In addition, we labeled and tracked acidic organelles using lysotracker red staining. Results demonstrated that the fluorescence intensity was higher in follicles of FSH-treated mice (Figure 1b). Western blot results showed that the lipid conjugation of free LC3-I to the autophagic membraneassociated LC3-II was enhanced in MGCs following FSH treatment and that degradation of the autophagy receptor SQSTM1 (p62) was enhanced (Figures 1c and d). Thus, after intraperitoneal injection of $\mathrm{FSH}$, autophagy signaling in MGCs from antral and preovulatory follicles was significantly increased and remained at a relatively high level.

FSH promotes MGC autophagy through the AKT-mTOR pathway. To further investigate the molecular mechanism by which FSH induces autophagy in MGCs, we focused on molecular regulation within the $12 \mathrm{~h}$ following administration. As shown in Figures $2 \mathrm{a}$ and $\mathrm{b}$, western blot results showed that LC3-II protein expression was significantly increased after $\mathrm{FSH}$ treatment and peaked at $6 \mathrm{~h}$. Interestingly, the expression of LC3-I was significantly increased at $1.5 \mathrm{~h}$ (data not shown). We hypothesize that the activation of LC3-I is a preparation for cell autophagy because LC3-II can be distinguished from LC3-I by its increased mobility. The expression of p62 was increased within $3 \mathrm{~h}$ after administration and decreased over the next $9 \mathrm{~h}$. These results demonstrated that autophagy is rapidly activated and maintained at a high level up to $12 \mathrm{~h}$ after administration. FSH activates multiple downstream signaling pathways in GCs, including PKA, PI3K, AKT-mTOR, p38-MAPK, and ERK1. ${ }^{22}$ Linking them, mTOR acts as a central sensor of growth factors, nutritional condition, and energy status, and plays a dominant role in autophagy. ${ }^{23}$ Our results indicated that AKT, mTOR, and S6K1 (downstream effector of mTOR) expression levels were enhanced by FSH stimulation when compared with the control group. The expression of $\mathrm{p}$-AKT was induced at $1.5 \mathrm{~h}$ after FSH stimulation, but returned to the basal level at $9 \mathrm{~h}$. p-mTOR and p-S6K1 expression levels were also induced at $1.5 \mathrm{~h}$ after $\mathrm{FSH}$ stimulation and then decreased significantly when compared to the control group (Figure 2a, bottom, Figure 2c). In addition, the effect of the mTOR activator, MHY1485, (10 mg/kg, 2 days) before FSH treatment was investigated. The results suggested that MHY1485 blocked the autophagy signaling induced by FSH. p-mTOR and $\mathrm{p}$-S6K1 expression levels were maintained at a high level in the presence of MHY1485 (Figure 2d, bottom, Figure 2f), whereas LC3 expression showed no marked a 0 LC3

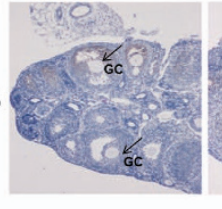

b

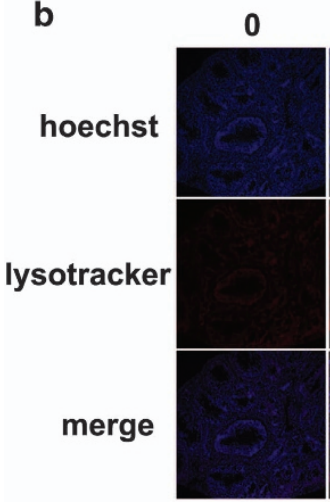

12

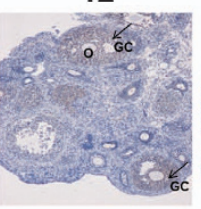

24

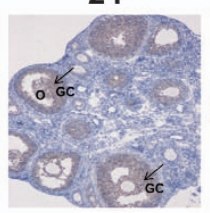

48

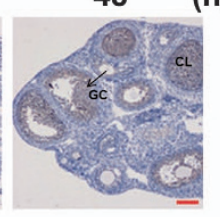

(h)

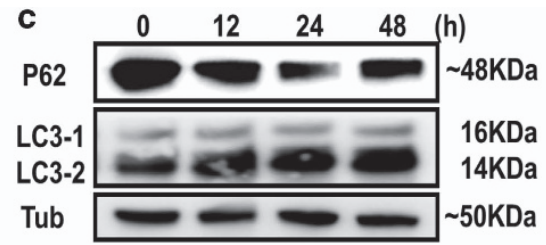

12

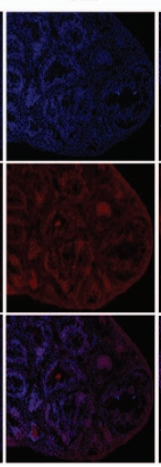

24

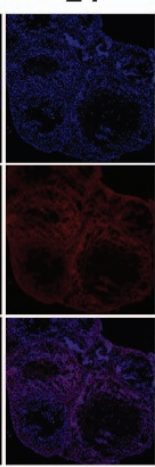

48

(h) d
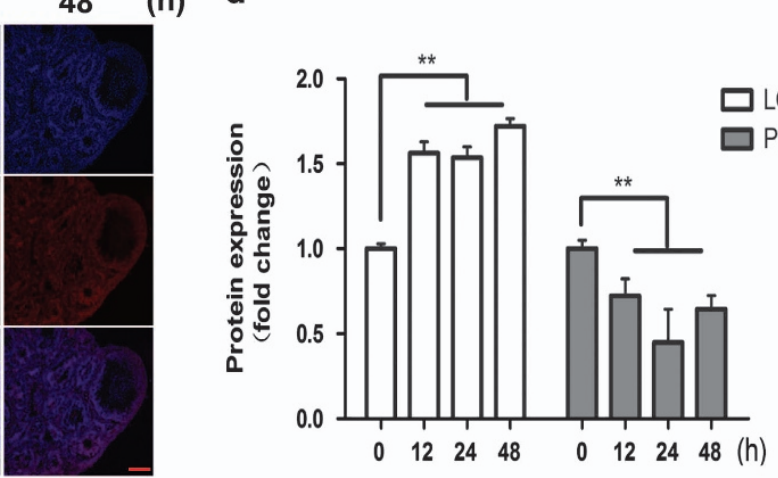

Figure 1 FSH induces MGC autophagy in vivo. (a) Mice were intraperitoneally injected with FSH. LC3 expression of follicular MGCs in the ovary sections was increased after FSH injection. Ovary sections were immunostained with anti-LC3 as described in Materials and Methods section, and autophagy was assessed at $0,12,24$, and $48 \mathrm{~h}$. Bar $=100 \mu \mathrm{m}$. O, oocyte; GC, granulosa cells; CL, corpora luteum. (b) FSH increased lysotracker red staining in MGCs. Lysotracker red staining (red) and DAPI (blue) was performed after treatment. Bar $=100 \mu \mathrm{m}$ (c) FSH increased the conversion of LC3-I into LC3-II and decreased the p62 protein level in MGCs. Western blot results of extracts from cells treated with FSH $(n=3)$. $\alpha$-Tubulin was used as a loading control. (d) Quantitative analysis of the data presented in $\mathbf{c}$ (mean \pm S.E of independent experiments, $n=3$, $\left.{ }^{* *} P<0.01\right)$ 
a

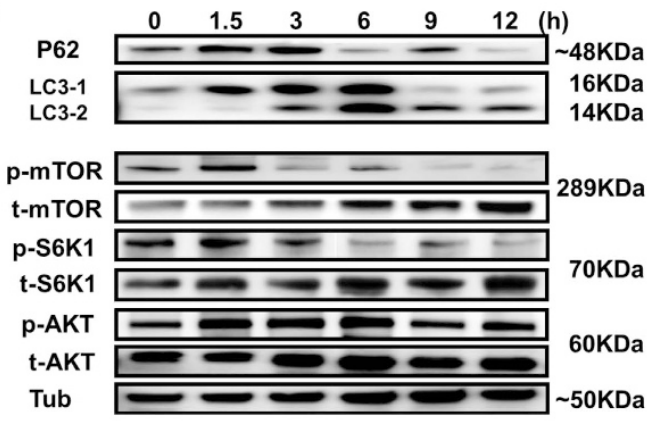

b
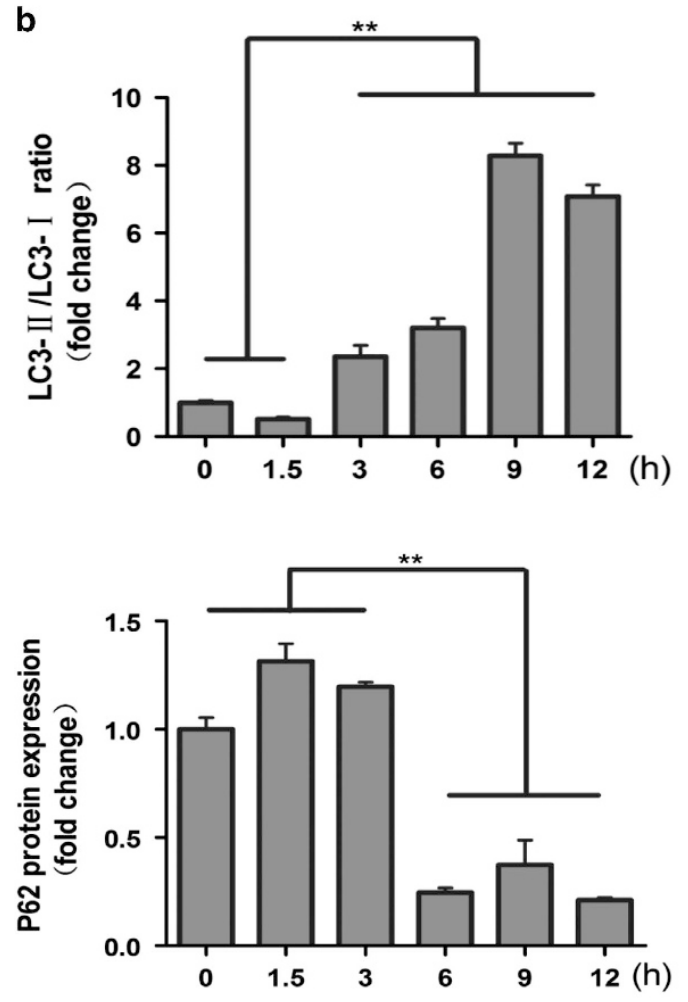

C

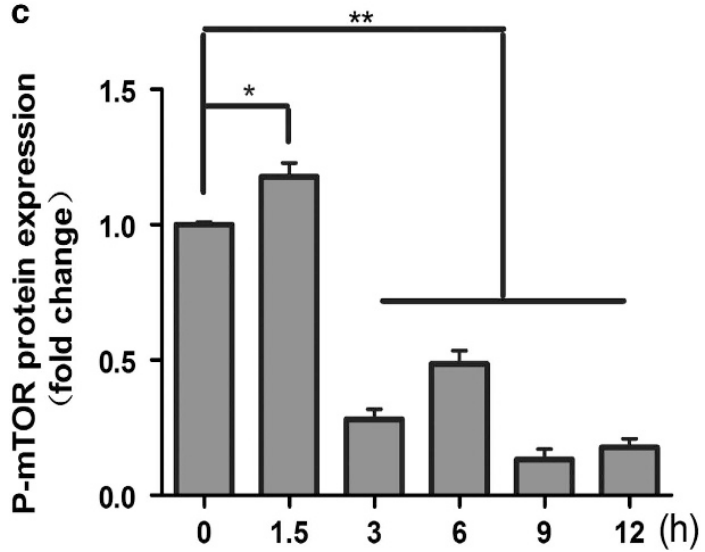

d
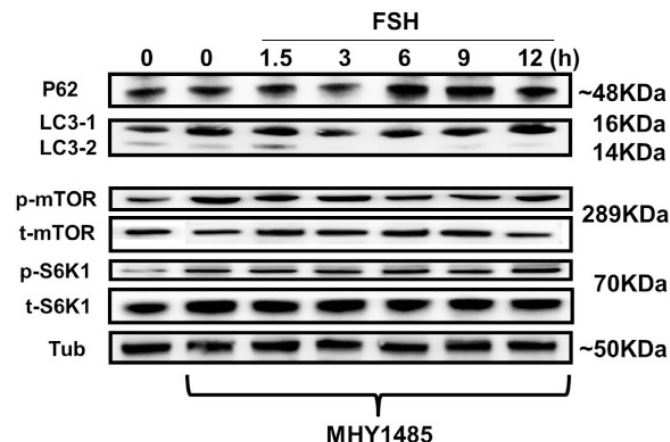

e
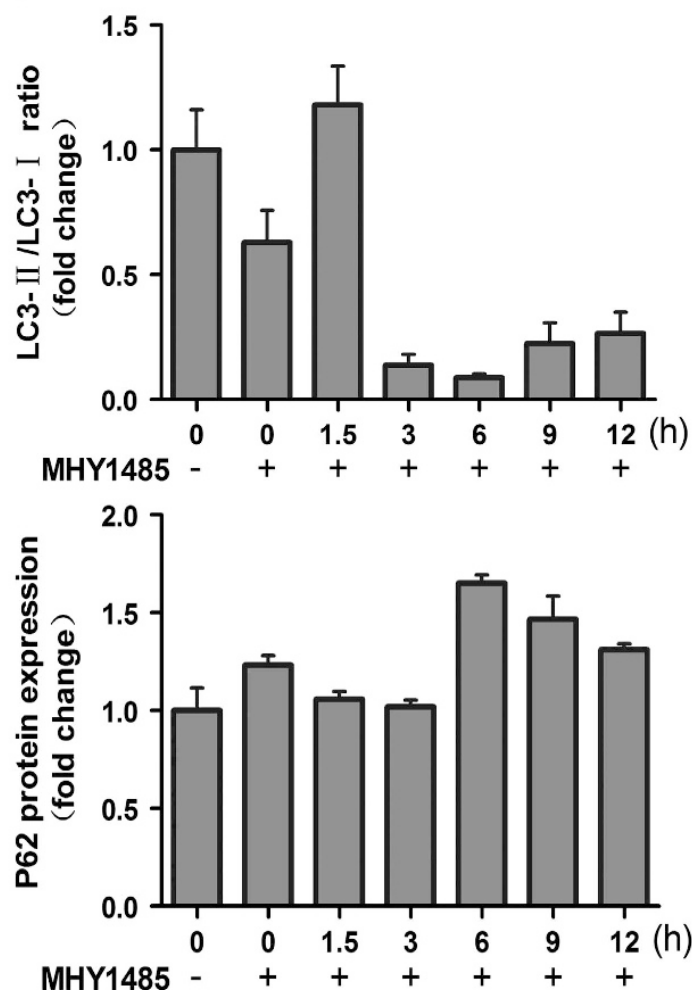

f

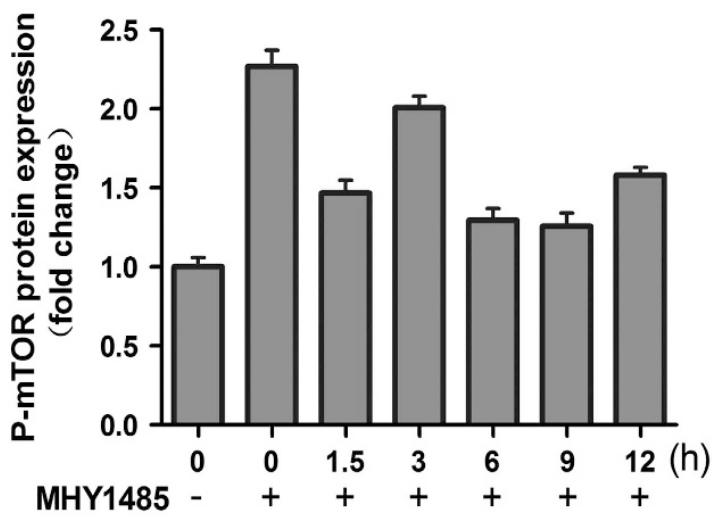

Figure 2 FSH regulates the AKT-mTOR pathway. (a) FSH increased the conversion of LC3-I into LC3-II and decreased the p62 protein level in MGCs at $12 \mathrm{~h}$. The level of p-mTOR and p-S6K1 was increased at $1.5 \mathrm{~h}$ and decreased at 3, 6, 9, and $12 \mathrm{~h}$ compared to that in the control group. $\alpha$-Tubulin was used as a loading control. (b) Quantitative analysis of protein level of LC3-II/LC3-I ratio and p62 in a, top. (c) Quantitative analysis of protein level of p-mTOR in a, bottom. (d) The effects of MHY1485 on MGCs autophagy induced by FSH injection at $12 \mathrm{~h}$. The protein level of p-mTOR and p-S6K1 was increased after MHY1485 treatment. LC3-I/LC3-I ratio was decreased and the level of p62 was increased after MHY1485 treatment. $\alpha$-Tubulin was used as a loading control. (e) Quantitative analysis of protein level of LC3-II/LC3-I ratio and p62 in d, top. (f) Quantitative analysis of protein level of $p$-mTOR in $\mathbf{d}$, bottom. Data are presented as means $\pm S$.E of three experiments. ${ }^{*} P<0.05$. ${ }^{* *} P<0.01$ 
change compared to that in the control group (Figure 2d, top, Figure 2e). These findings demonstrated that FSH induces MGCs autophagy through the AKT-mTOR signaling pathway and initiates a dynamic process occurring within $12 \mathrm{~h}$ posttreatment.

FSH upregulates HIF-1a and AMPK in MGCs. FSH is a powerful growth factor that promotes GC proliferation, ${ }^{24,25}$ as confirmed by our CCK-8 results during the $12 \mathrm{~h}$ period following FSH treatment (Supplementary Figure S1). Cell autophagy and apoptosis are tightly linked to cell metabolism. Excessive cell proliferation causes metabolic stress, including hypoxia and nutrition stress, promoting cell autophagy and death. ${ }^{26}$ Therefore, we investigated the expression of HIF-1a and AMPK by using qPCR and western blot. The results demonstrated that HIF-1a mRNA and protein expression was significantly upregulated (Figures $3 a$ and $\mathrm{c}$ ). Activation of AMPK was significantly enhanced between 3 and $12 \mathrm{~h}$ after $\mathrm{FSH}$ injection (Figures $3 \mathrm{~d}$ and e), while total AMPK expression did not change (Figures $3 b$ and $d$ ). In addition, the expression of a downstream factor, Beclin1, was also increased after FSH administration (Figure 3f). Recent reports indicated that reactive oxygen species (ROS) may lead to damage of cellular components and subsequently induce cell autophagy. ${ }^{27,28}$ Therefore, we measured the intracellular ROS level in MGCs after FSH injection within $12 \mathrm{~h}$. The level of intracellular ROS did not change significantly (Figure 3g). However, the mRNA levels of antioxidant enzymes, superoxide dismutase (SOD), catalase (CAT), and glutathione peroxidase (GPX), increased (Figure $3 \mathrm{~h}$ ). These results demonstrated that $\mathrm{FSH}$ leads to hypoxia and reduces nutritional status in MGCs. Moreover, FSH plays a role in protecting GCs against the effect of ROS by activating the antioxidant enzyme system.

HIF-1a is the critical factor in MGC autophagy. To determine the effect of FSH-mediated HIF-1 $a$ and AMPK activation on cell autophagy, MGCs, with or without $\mathrm{FSH}$, were treated with HIF-1a (Px-478) and AMPK inhibitors (Compound $\mathrm{C}$ ), and cell autophagy signaling was detected by western blot. The experimental protocol is described in Supplementary Figure S2. After pretreating mice with Px-478, the expression of HIF-1a was significantly decreased at days 2 and 3 (Figures $4 a$ and b). The LC3-II/LC3-I ratio was also significantly decreased at $12 \mathrm{~h}$ compared with that at $3 \mathrm{~h}$ after pretreatment with Px-478 (Figure 4c, top). In contrast, the expression of $\mathrm{p} 62$ was maintained at a high level after pretreatment with Px-478 (Figure 4c, bottom). Subsequently, we measured autophagy signaling in MGCs after AMPK inhibition. The results showed that the expression level of $\mathrm{p}$-AMPK was inhibited by Compound $\mathrm{C}$ injection (Figures 4d and e) and total AMPK expression was inhibited. However, the LC3-II/LC3-I ratio and the degradation of p62 did not change compared with those in the groups only treated with FSH (Figure 4f), suggesting that the AMPK signaling pathway is not crucial for the promotion of cell autophagy although p-AMPK is highly expressed following $\mathrm{FSH}$ injection. These results demonstrated that HIF-1a is primarily involved in FSH-regulated MGC autophagy.

FSH enhances MGC autophagy through HIF-1a in vitro. To further confirm the effects of HIF-1a on MGC autophagy, we monitored this process in MGC primary cultures in vitro. Since HIF-1a is unstable under conditions of normoxia, we used a chemical inducer of HIF-1a, which acts by stabilizing HIF-1a transcription factor, inhibiting its degeneration under normoxia. As shown in Figures $5 a$ and b, $\mathrm{FSH}$ in combination with $\mathrm{CoCl}_{2}$ significantly increased HIF-1a expression, suggesting that $\mathrm{FSH}$ functions as a positive regulator of HIF-1a expression. The ratio of LC3-II/LC3-I and p62 degradation increased in $\mathrm{FSH}$-treated MGCs compared with that in the $\mathrm{CoCl}_{2}$-only group (Figure $5 \mathrm{c}$ ). Consistent with the results presented in Figure $3 \mathrm{f}$, in the presence of $\mathrm{CoCl}_{2}$, FSH significantly increased Beclin1 expression (Figure $5 \mathrm{~d}$, left). We also detected the expression of Bnip3, a member of the $\mathrm{BH}$-only protein family that contains a hypoxia response element in the promoter ${ }^{29}$ and is associated with autophagy in the hypoxia model. ${ }^{30}$ The results demonstrated that Bnip3 expression was significantly enhanced after treatment with $\mathrm{FSH}$ and $\mathrm{CoCl}_{2}$ compared to that in MGCs treated with $\mathrm{CoCl}_{2}$ alone (Figure $5 \mathrm{~d}$, right). Immunofluorescence studies indicated that $\mathrm{FSH}$-induced HIF-1a significantly increased the formation of GFP-LC3 puncta, suggesting increased autophagy signaling under these conditions (Figures $5 \mathrm{e}$ and $\mathrm{g}$ ). Moreover, we used the autophagy-flux inhibitor, Bafilomycin A1, which prevents lysosome degradation, thus increasing punctate GFP-LC3 exclusively when autophagy is active. Bafilomycin A1 treatment indicated that $\mathrm{FSH}$ significantly increased the autophagy flux, as monitored by GFP-LC3 puncta (Figures $5 f$ and $g$ ). In addition, Bafilomycin A1 significantly increased the GFP-LC3 puncta in $\mathrm{Cocl}_{2}$ treated cells regardless of $\mathrm{FSH}$. These results demonstrated that FSH promotes MGC hypoxia, further enhancing autophagy in vitro.

Blocking HIF-1a, Beclin1, and Bnip3 attenuates FSHinduced autophagy in MGCs. To further test whether loss of HIF-1a function decreases autophagy in MGCs after co-treatment with $\mathrm{FSH}$ and $\mathrm{CoCl}_{2}$, si-HIF-1a (siRNA HIF-1a) was used to knockdown HIF-1a expression induced by

Figure 3 The effect of FSH on HIF-1 $\alpha$ and AMPK in MGCs. (a) FSH injection increased HIF- $1 \alpha$ mRNA level. The HIF-1 $\alpha$ mRNA level was determined by real-time PCR. The relative expression data were normalized to the amount of GAPDH. (b) FSH treatment did not have an effect on AMPK mRNA expression. The AMPK mRNA level was determined by real-time PCR. GAPDH was used as an internal control. (c) FSH treatment increased HIF- $1 \alpha$ protein expression at $3,6,9$, and $12 \mathrm{~h}$ compared to 0 and $1.5 \mathrm{~h}$. The relative expression data were normalized to $\alpha$-Tubulin. (d) Western blot analysis of total AMPK and p-AMPK levels in MGCs after FSH injection at $12 \mathrm{~h}$. $\alpha$-Tubulin was used as a loading control. (e) AMPK activity was detected after FSH treatment. Detection was performed as described in Materials and Methods section. (f) Beclin1 protein expression in MGCs treated with FSH. Relative protein level was measured by densitometry and normalized to $\alpha$-tubulin. (g) The cellular ROS level in MGCs after FSH treatment. Detection was performed as described in Materials and Methods section. (h) The effect of FSH on MnSOD, CAT, and GPX mRNA level determined by real-time PCR. The data are means \pm S.E; $(n=3) .{ }^{*} P<0.05 .{ }^{* *} P<0.01$ 
FSH. MGCs were transfected with si-HIF-1a and then treated with $\mathrm{FSH}$ and $\mathrm{CoCl}_{2}$. HIF-1a expression was inhibited by si-HIF-1a (data not shown). In addition, autophagy signaling was decreased (Figure 6a). Consistently, transfection with si-HIF-1a also decreased GFP-LC3 puncta observed by immunofluorescence (Figure 6b). Next, we investigated the a

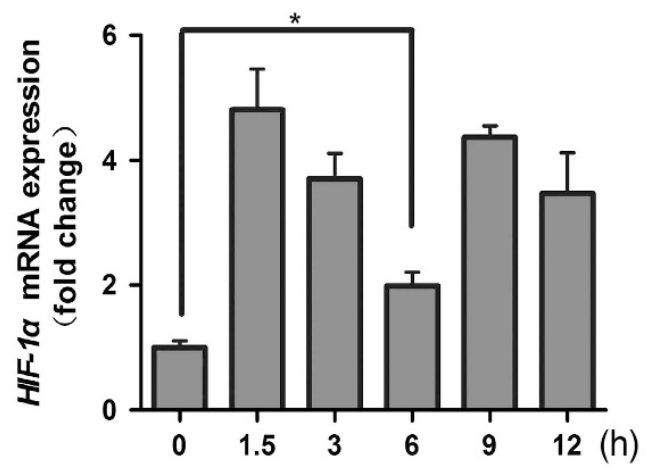

C
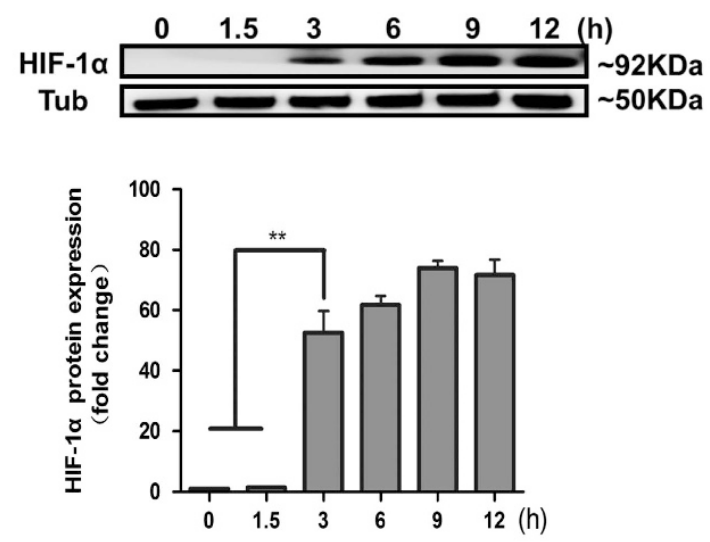

e

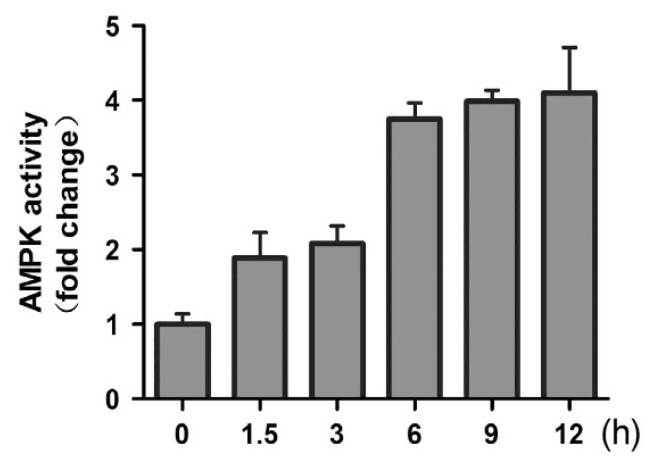

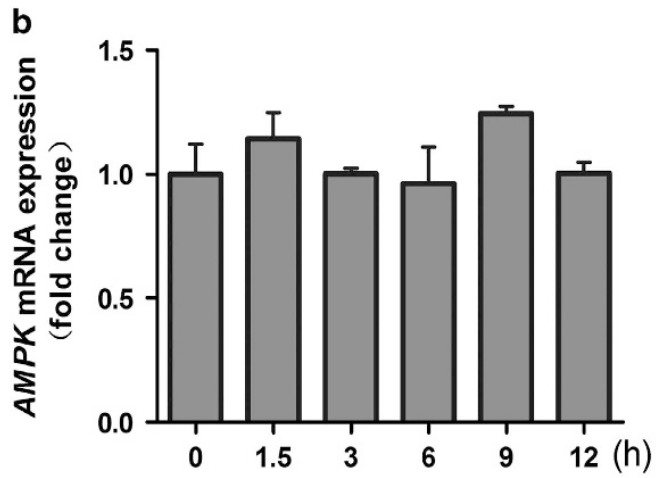

d
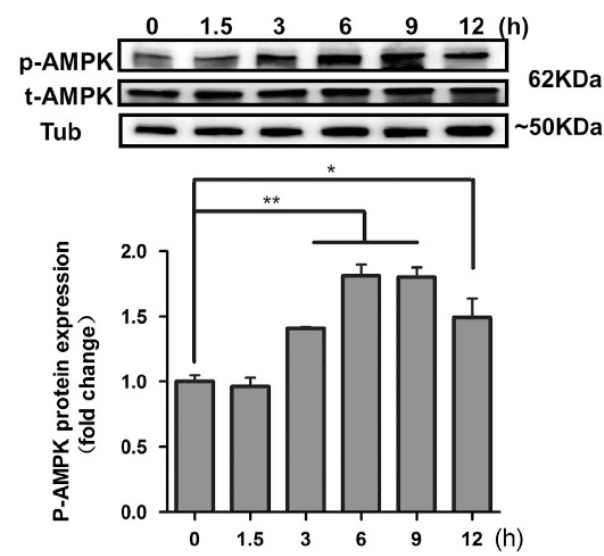

f
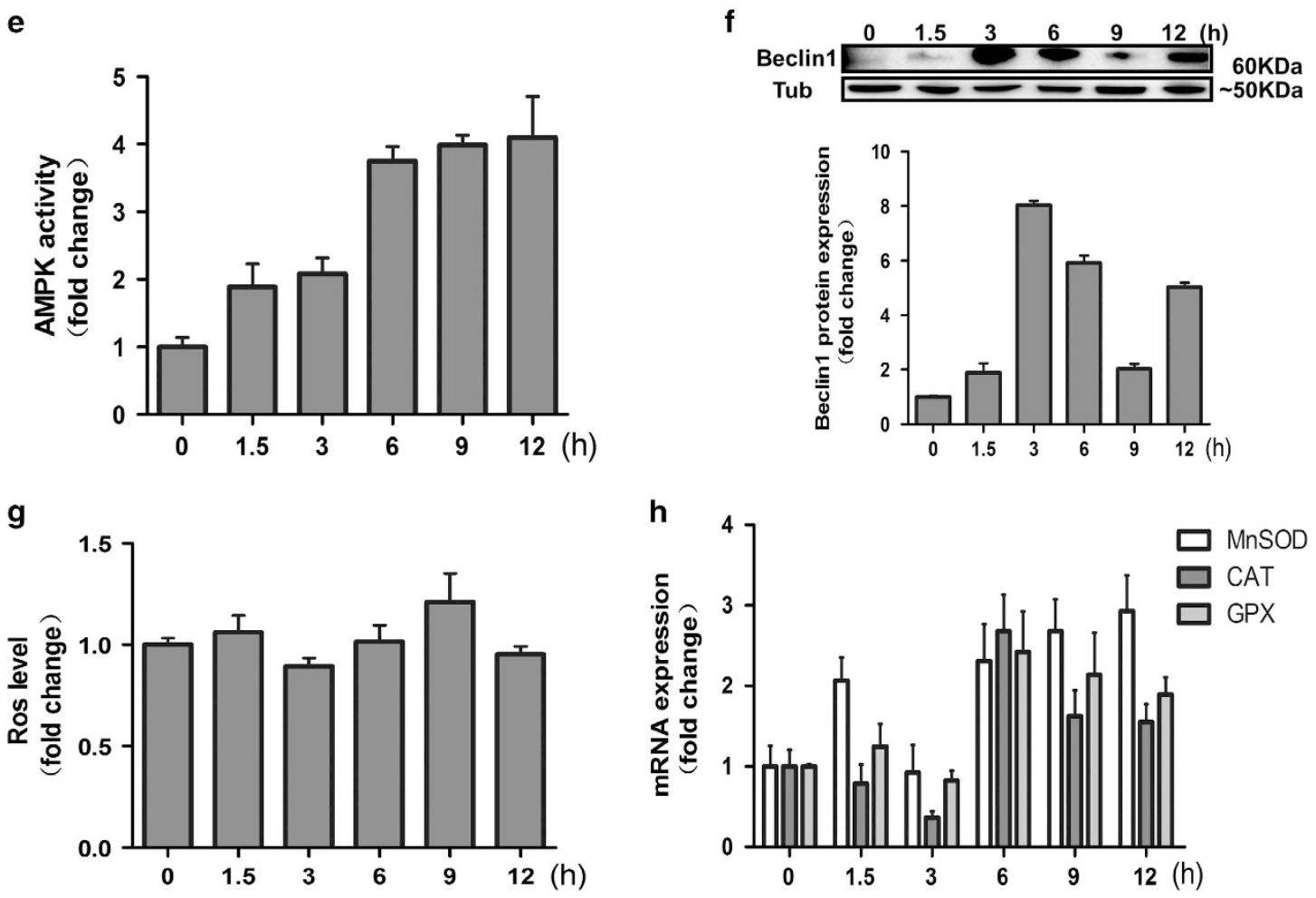

h

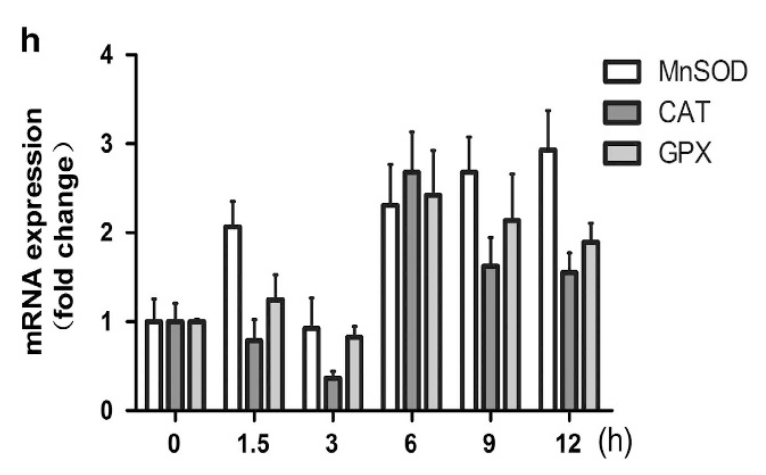



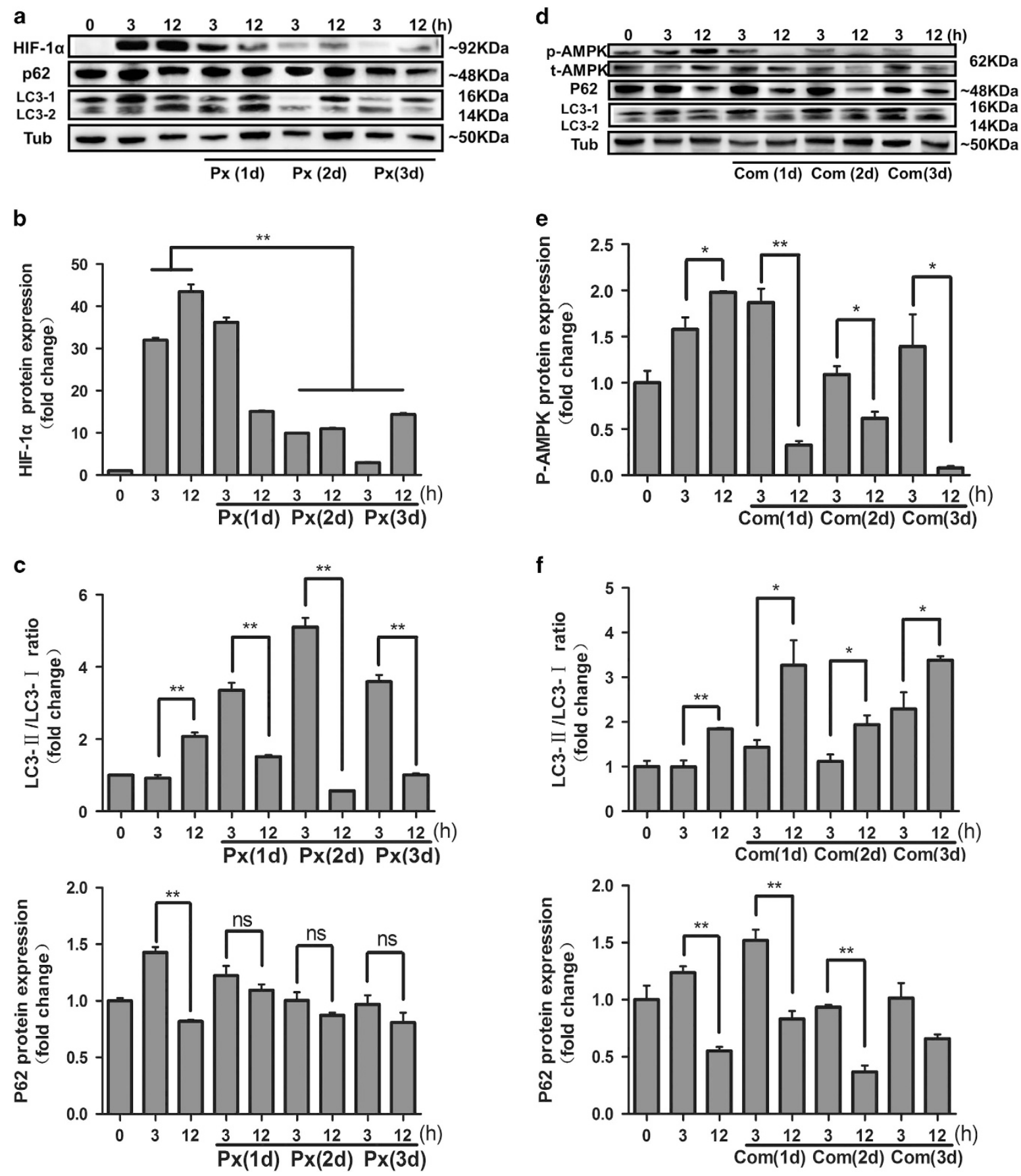

Figure 4 Blocking HIF-1 $\alpha$ decreases FSH-induced autophagy in MGCs. (a) The effects of co-treatment of Px-478 with FSH on HIF-1 $\alpha$, p62, and LC3 protein levels, as detected by western blot. Relative protein levels were measured by densitometry and normalized to $\alpha$-tubulin (b) Quantitative analysis of protein level of HIF-1 $\alpha$ in a. (c) Quantitative analysis of protein level of LC3-II/LC3-I ratio and p62 in a. (d) The protein level of total AMPK, p-AMPK, p62, and LC3 after co-treatment of Compound C with FSH. Relative protein levels were normalized to $\alpha$-tubulin. (e) Quantitative analysis of protein level of p-AMPK in $\mathbf{d}$. (f) Quantitative analysis of protein level of LC3-II/LC3-I ratio and p62 in d. All experiments were performed in triplicate. ${ }^{*} P<0.05$. ${ }^{*} P<0.01$. Com, compound C; NS, not significant; Px, Px-478

role of downstream factors of HIF-1a (Beclin1 and Bnip3) on autophagy. Two siRNA (si-Bec and si-Bnip3) were used to knockdown Beclin1 and Bnip3 expression. Results demonstrated that Beclin1 and Bnip3 expression was significantly suppressed after transfection with siRNA (Figures $6 \mathrm{c}$ and d).
Autophagy signaling was inhibited, even under conditions of hypoxia as indicated by decreased LC3-II/LC3-I ratio, inhibited p62 degradation, and decreased formation of GFPLC3 puncta (Figures $6 e$ and $\mathrm{f}$ ). In addition, the differences between FSH treated and untreated HIF1a, Beclin1, and 
a

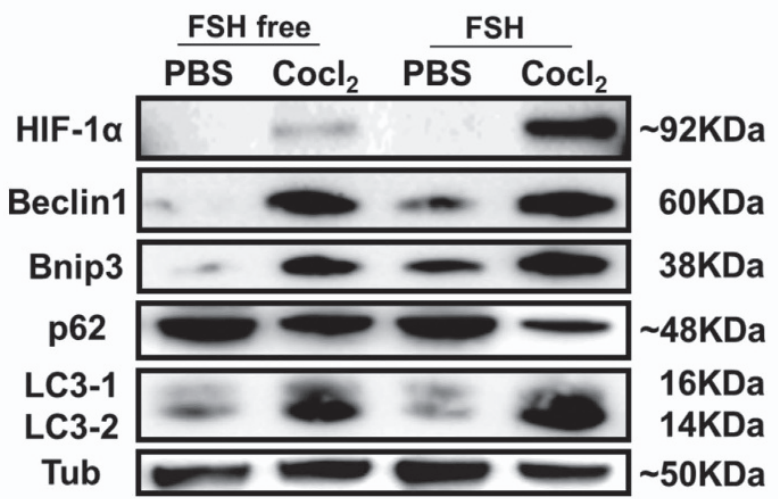

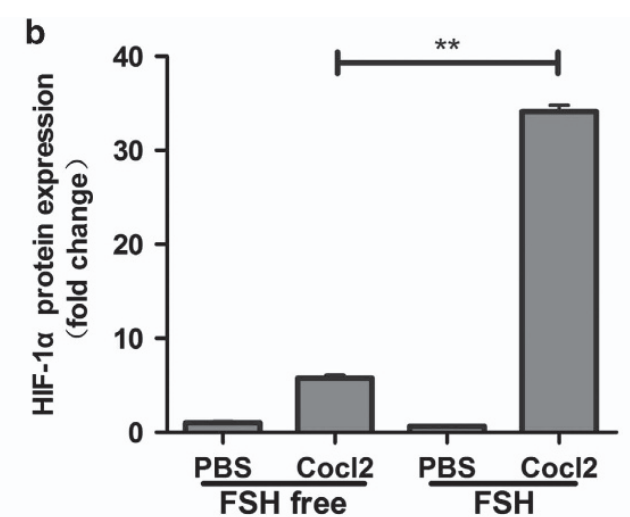
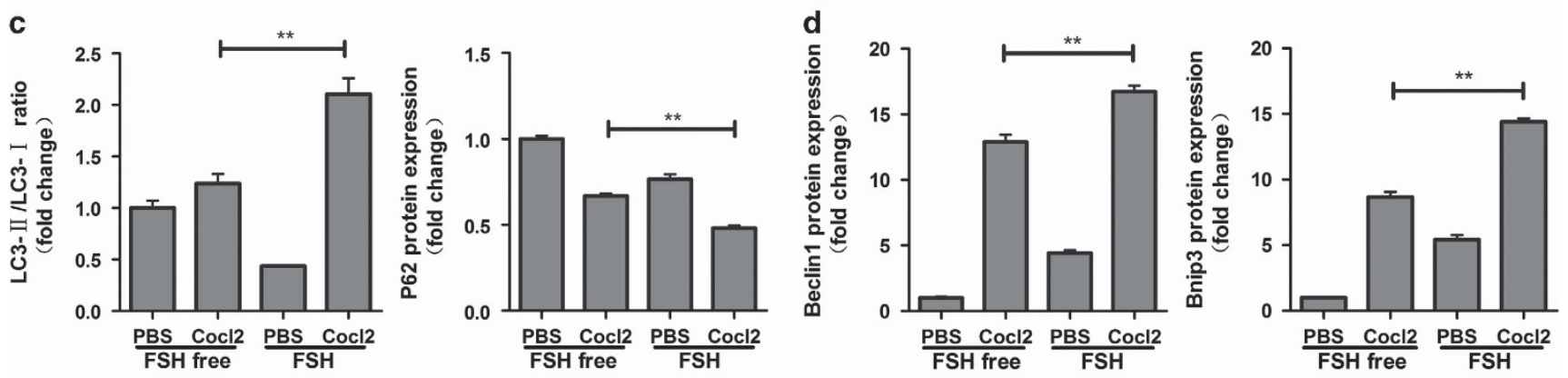

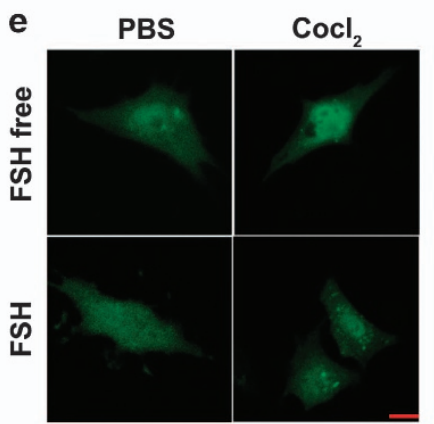

f

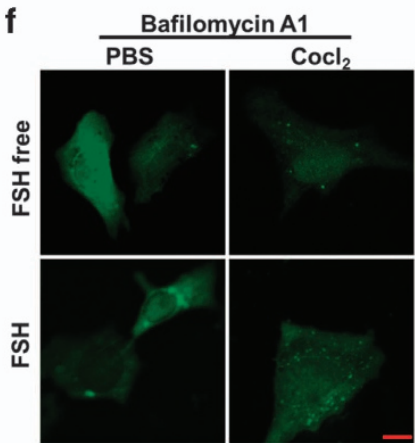

g

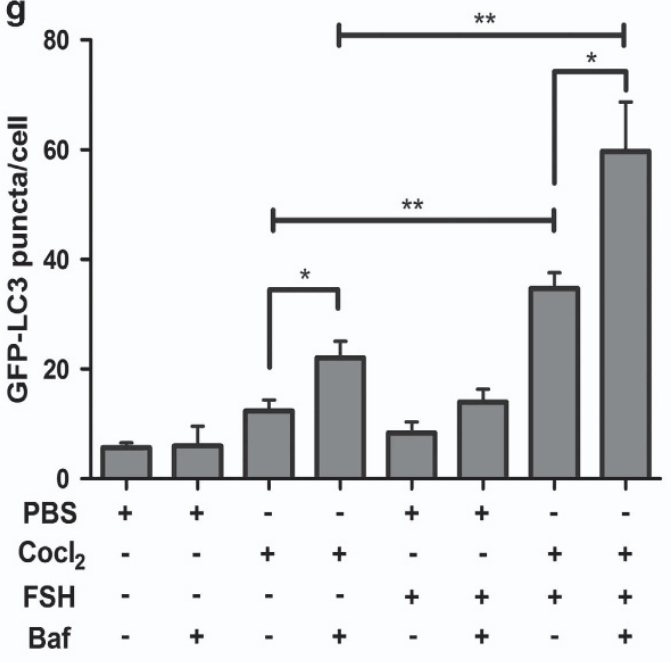

Figure 5 FSH promotes MGCs autophagy by regulating HIF-1 $\alpha$ in vitro. (a) HIF-1 $\alpha$, Beclin1, Bnip3, p62, and LC3 protein levels in MGCs. After $4 \mathrm{~h}$ of cultured with CoCl , the medium was replaced and FSH was added. Cells were harvested and the indicated proteins were detected by western blot after $6 \mathrm{~h}$. Relative protein levels were normalized to $\alpha$ tubulin. (b) Quantitative analysis of HIF-1 $\alpha$ protein levels in a. (c) Quantitative analysis of LC3-II/LC3-I ratio and p62 protein levels in a. (d) Quantitative analysis of Beclin1 and Bnip3 expression in a. (e) MGCs were transfected with plasmid encoding GFP-LC3. Cells were treated with $\mathrm{CoCl}_{2}$ or FSH after $48 \mathrm{~h}$ and autophagy was assessed. Bar $=10 \mu \mathrm{m}$. (f) Autophagy flux in cells from (e). Cells were treated with Bafilomycin A1 (50 nM) for $4 \mathrm{~h}$ before analysis. Bar $=10 \mu \mathrm{m}$. (g) Quantitative analysis of the data in e and f. The data are mean \pm S.E.; $(n=3) .{ }^{*} P<0.05 .{ }^{* *} P<0.01$

Bnip3 down-regulated cells are not significant (Supplementary Fig. S3). Together, these results indicated that Beclin1 and Bnip3 are critical factors in $\mathrm{FSH}$-induced autophagy, mediated by modulation of HIF-1a.
FSH has a protective effect on follicular development by increasing the activity of mitochondrial clearance. We next investigated the relationship between $\mathrm{FSH}$-induced autophagy and follicular development. Chloroquine, an 
autophagy inhibitor, induced the accumulation of LC3-II and p62 in FSH-treated GCs by blocking the later stage of autophagy (Figure 7a). Interestingly, FSH treatment signifi-

a

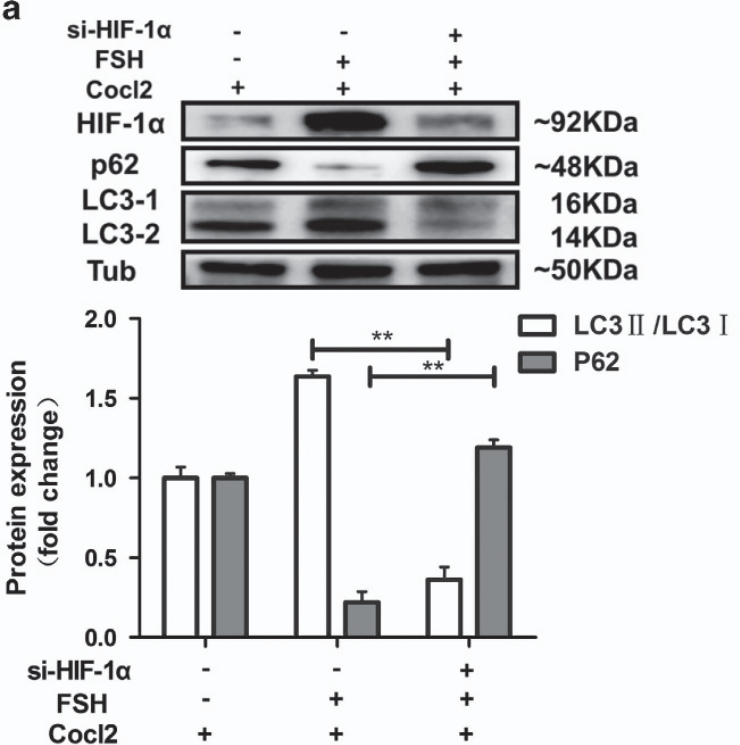

C
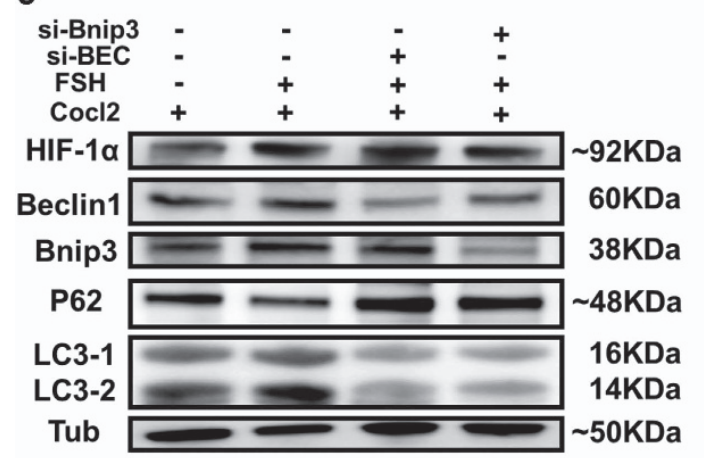

e

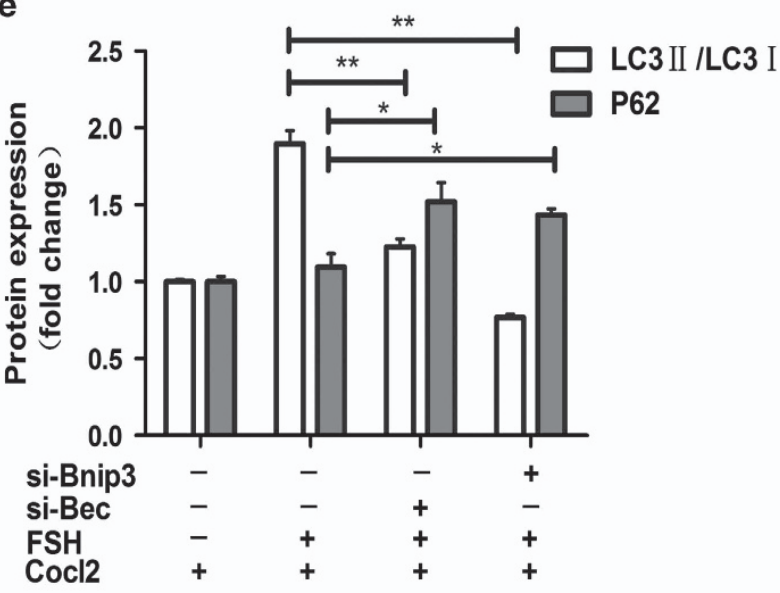

cantly increased the size and weight of the ovary, which were reduced by chloroquine (Figures $7 \mathrm{~b}$ and $\mathrm{c}$ ). However, MGC apoptosis was not significantly affected by autophagy

b
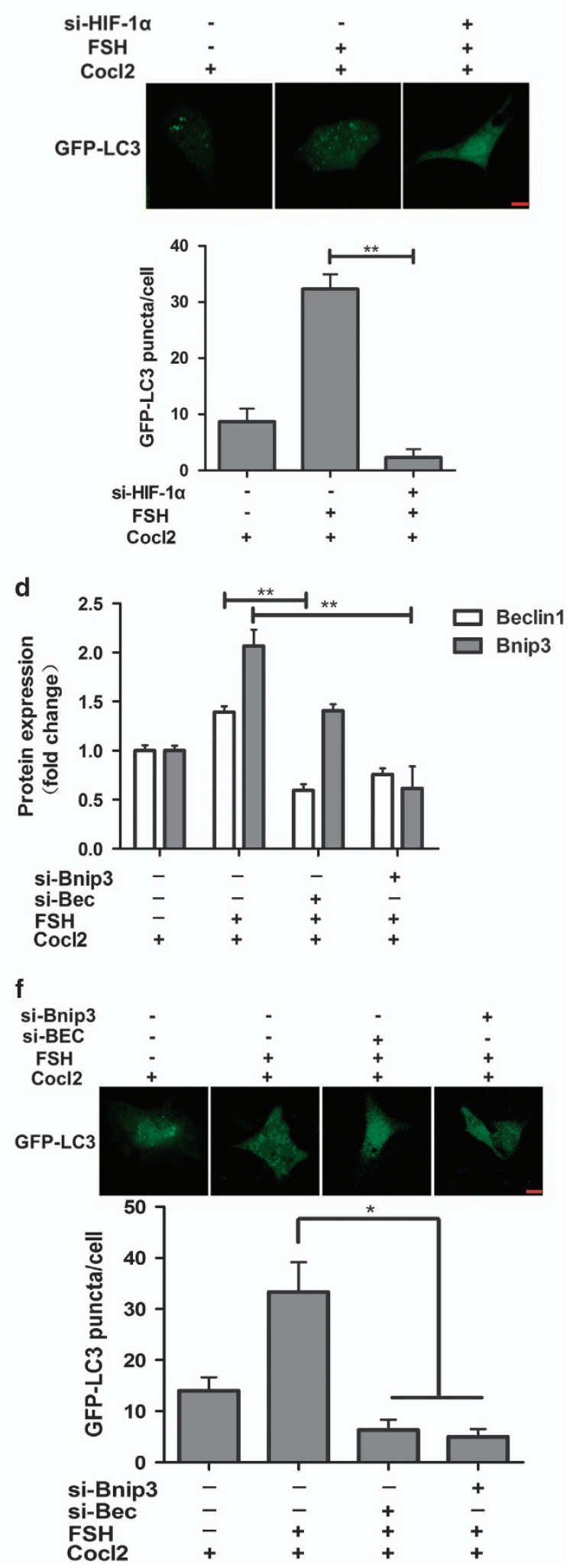
inhibition, assessed by monitoring caspase-3 activity, and the expression of apoptosis-related genes (Figure $7 d$ and Supplementary Figure S4). Previous reports indicated a mutual regulation between apoptosis and autophagy in the death signaling process mediated by mitochondria. ${ }^{31,32}$ Thus, we investigated whether $\mathrm{FSH}$-mediated autophagy affected mitochondrial membrane potential $(\Delta \Psi(\mathrm{m}))$. JC-1 staining experiments indicated that the increased mitochondrial membrane potential by FSH was abolished by autophagy inhibition (Figures 7e and f). In addition, we assessed the expression of the PINK1-Parkin system that belongs to the mitophagy pathway. Western blot indicated that PINK1 expression increased in MGC treated with FSH, and PINK1 level further increased after chloroquine treatment (Figures $7 \mathrm{~g}$ and $\mathrm{h}$ ). However, no marked change of Parkin expression was detected (Figure 7g), as Parkin could promote mitophagy by changing the mitochondrial location. ${ }^{33}$ Moreover, the loss of mitochondria resulting from mitophagy was decreased, which was indicated by mitochondrial membrane protein, Tom20 protein expression (Figures $7 g$ and $h$ ). Taken together, these data demonstrated that mitophagy induction via the PINK1-Parkin pathway is an important mechanism of FSHmediated follicular growth and development.

FSH-induced autophagy in MGCs is associated with cell proliferation. Autophagy is required for the cyclic phase of GC proliferation and differentiation. ${ }^{34}$ Thus, we investigated the potent function of autophagy in FSH-mediated cell proliferation. qPCR results revealed that cell proliferation was inhibited, mainly reflected in cyclinA2 and cyclinD2 expression (Figure 8a). To better assess cell proliferation deregulation, cell cycle, and cell proliferation were investigated. Flow cytometry showed that FSH and chloroquine co-treatment resulted in a small population of cells in the G2/ $\mathrm{M}$ phase when compared with the FSH-treated group (Figure 8b), suggesting a cell cycle delay in $S$ phase caused by autophagy inhibition. As shown in Figure 8c, chloroquine significantly attenuated the increased number of EdU-labeled cells following FSH treatment (Figures $8 \mathrm{c}$ and d), as well as the number of living/viable cells detected by CCK-8 assay (Supplementary Figure S5). Therefore, FSH-induced autophagy promotes MGC proliferation and follicular development. In addition, the expression of genes involved in estrogen biosynthesis and steroidogenic regulation associated with follicle development was detected by qPCR. Interestingly, the expression of $3 \beta-H S D$ was enhanced. In contrast, INHa expression was decreased compared with $\mathrm{FSH}$ only treatment (Figure 8e). To further demonstrate that autophagy is necessary for the development of follicles, we performed a hematoxylin and eosin (H\&E) staining assay. The increased number of antral follicles and preovulatory follicles after FSH treatment was reduced by chloroquine (Figures $8 \mathrm{f}$ and $\mathrm{g}$ ). Overall, these results provided evidence that FSH-mediated autophagy is associated with GC proliferation and follicular development.

\section{Discussion}

During follicular development, a proportion of ovarian follicles are removed by atresia prior to maturation in order to promote energy investment and ovulation of viable follicles. Autophagy captures and degrades intracellular components such as abnormal proteins and damaged organelles to sustain metabolism and homeostasis. In particular, autophagy is closely related with the remodeling of follicle cells during the process of follicular development. ${ }^{35,36}$ Signs of autophagy depend on gonadotropin dose, age, and body weight in freshly harvested human $\mathrm{GCs}^{37}$ suggesting that autophagy is common in mammalian ovaries where most follicles and cells are in a highly regulated state, balancing hormonal and environmental stimulus. However, the underlying molecular mechanism is still unknown.

FSH is an important survival factor leading to selection and survival of growing follicles during development. ${ }^{38}$ The physiological functions of $\mathrm{FSH}$ are achieved by activating several signaling cascades in GCs, including PKA, PKB, p38-MAPK, and ERK1/2, which in turn modulate $>100$ different target genes. ${ }^{39}$ These downstream factors are directly or indirectly involved in autophagy regulation. ${ }^{40-43}$ In the mouse ovary, TGF $\beta$ signaling was activated after exposure to $\mathrm{FSH}$ and $\mathrm{LH}^{44}$ Inhibition of TGF $\beta$ signaling by blocking TGF $\beta$ R2 significantly decreased $\mathrm{FSH}$-mediated autophagy signaling. ${ }^{45}$ In porcine GCs, FSH increased the level of inhibitor of NF- $\kappa \mathrm{B}\left(\mathrm{I}_{\kappa} \mathrm{B}\right)$ protein and subsequently increased autophagy via JNK signaling. ${ }^{46}$ In this study, we demonstrated that FSH administration enhanced autophagy in MGCs. Injection of FSH increased endogenous LC3 staining, the LC3-II/LC3-I ratio, p62 degradation, and enhanced lysotracker staining in MGC. These are the most widely used tests for autophagy determination. ${ }^{47}$

mTOR is a downstream regulator of PKB, which senses nutrient, energy and oxygen availability, and growth factor signaling, and plays an important role in autophagy. ${ }^{48}$ In this study, we introduced mTOR as the main factor affecting autophagy induced by FSH in MGCs. FSH activates the expression of $\mathrm{p}-\mathrm{mTOR}$ and promotes the accumulation of LC3-I within $1.5 \mathrm{~h}$. After $3 \mathrm{~h}$, FSH significantly enhanced signs of autophagy by inhibiting the expression of $p$-mTOR. In addition, the mTOR activator, MHY1485, suppressed the autophagy level following FSH treatment. These results suggest that $\mathrm{FSH}$ regulates autophagy through mTOR inactivation.

Figure 6 Knockdown of HIF-1 $\alpha$, Beclin1, and Bnip3 attenuates autophagy induced by FSH in MGCs. (a) HIF-1 $\alpha$, p62, and LC3 protein levels in MGCs. After MGCs were transfected with HIF- $1 \alpha$ siRNA for $24 \mathrm{~h}$, cells were treated with FSH or $\mathrm{CoCl}_{2}$. si-HIF-1 $\alpha$, siRNA-HIF- $1 \alpha$. Relative protein levels were normalized to $\alpha$-tubulin. (b) MGCs were transfected with si-HIF-1 $\alpha$ and GFP-LC3 plasmid, and GFP puncta were detected by immunofluorescence after $\mathrm{FSH}_{\text {or }} \mathrm{CoCl}_{2}$ treatment. Bar $=10 \mu \mathrm{m}$. (c) Western blot analysis of HIF-1 $\alpha$, Beclin1, Bnip3, p62, and LC3 protein levels in MGCs after transfection with siRNA. si-Bnip3, siRNA-Bnip3; si-Bec, siRNA-Beclin1. Relative protein levels were normalized to $\alpha$-tubulin (d) Quantitative analysis of Bnip3 and Beclin1 protein levels in c. (e) Quantitative analysis of LC3-II/LC3-I ratio and p62 protein levels in c. (f) MGCs were transfected with si-Bnip3 or si-Beclin1 together with GFP-LC3 plasmid. Cell autophagy was detected after $48 \mathrm{~h}$ with FSH or CoCl $\mathrm{Cl}_{2}$ treatment. Bar $=10 \mu \mathrm{m}$. All experiments were performed in triplicate. ${ }^{*} P<0.05$. ${ }^{* *} P<0.01$ 
Hypoxia is a pathological condition in which the body or a region of the body is deprived of an adequate oxygen supply. Evidence suggests that HIF-1a plays an essential role in angiogenesis, ${ }^{49}$ cell proliferation/survival, ${ }^{50}$ and glucose/iron metabolism. ${ }^{51,52}$ Consistent with our results (Figure 2a, Figures $3 \mathrm{a}$ and $\mathrm{c}$ ), a previous study indicated HIF-1a is a

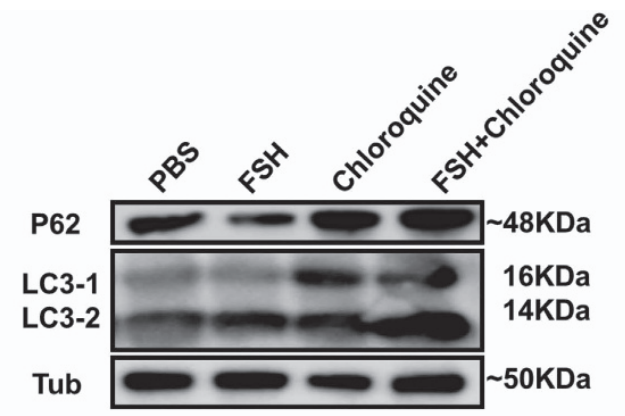

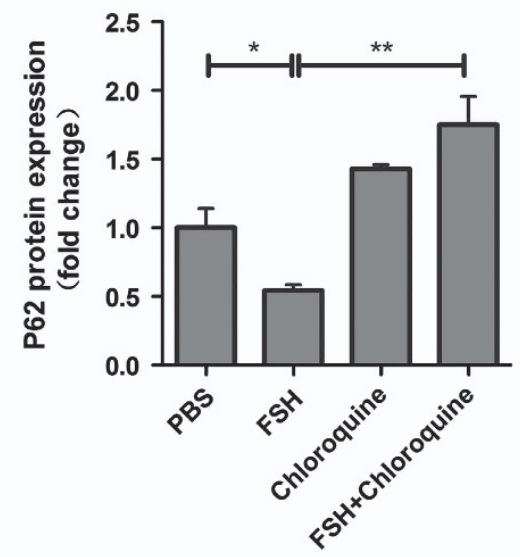

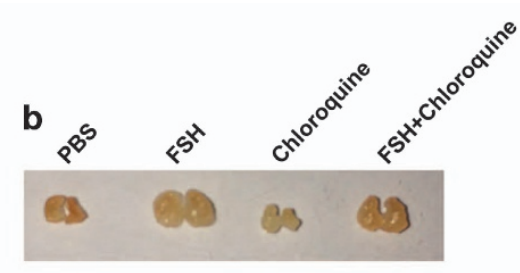

c
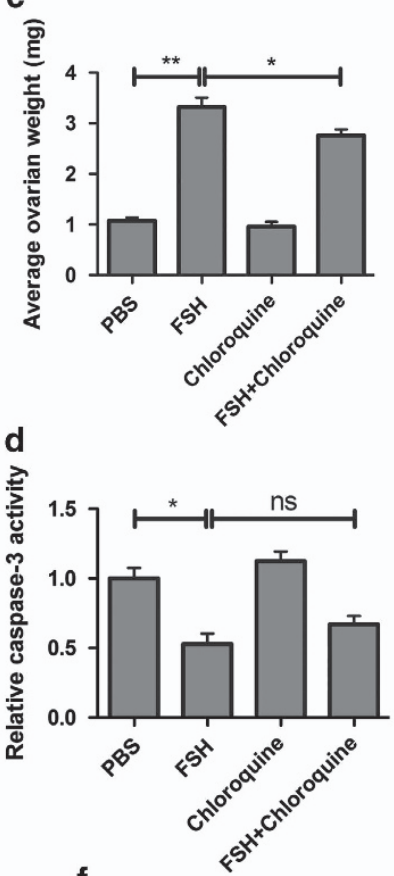

e

PBS

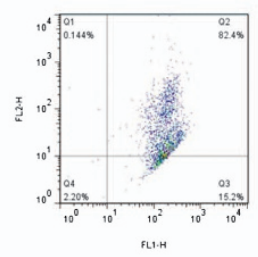

Chloroquine

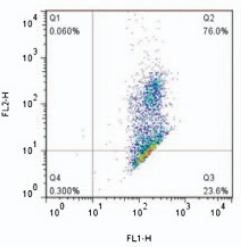

FSH

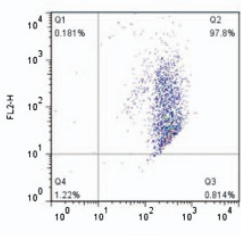

fut

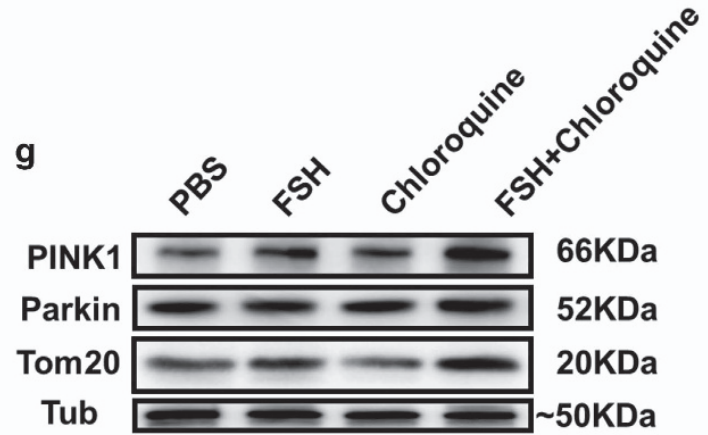

FSH+Chloroquine
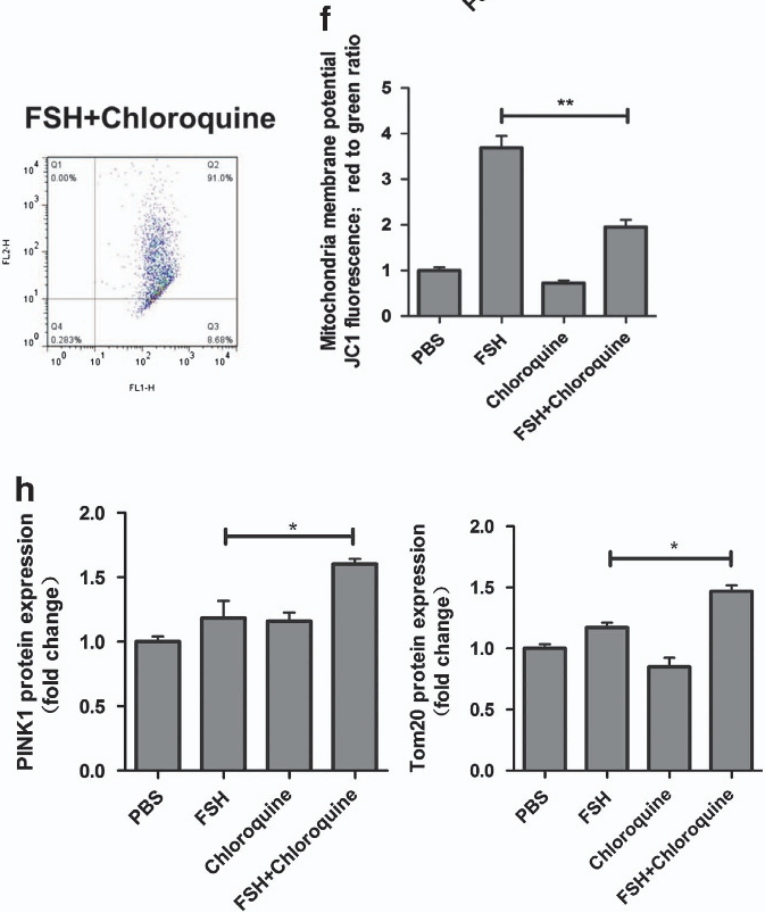
activated in FSH-stimulated ovarian cancer cells, SKOV-3, and that the PI3K/AKT signaling is upregulated. ${ }^{53}$ In the ovary, excessive cell proliferation induced by gonadotropins promotes the accumulation of HIF-1a and leads to hypoxia. ${ }^{54}$ Here, we identified HIF-1a as an inducible factor after FSH treatment. Injection of FSH significantly increased HIF-1a expression in vivo and vitro. Our results are consistent with a recent report demonstrating that HIF-1a is a downstream factor of $\mathrm{FSH}$ in rat GCs. ${ }^{55}$ Remarkably, HIF-1a mRNA decreased at $6 \mathrm{~h}$ without reflecting a modulation of HIF1-a protein level until $12 \mathrm{~h}$ (Figures $3 \mathrm{a}$ and $\mathrm{c}$ ), indicating that $\mathrm{HIF}-1 a$ transcriptional and post-transcriptional regulation is also involved in this process.

Recent studies indicated that autophagy has a complex and close link with hypoxia. ${ }^{56,57}$ Evidence from various mammalian cell types indicates that HIF-1a induces autophagy by activating Bnip3. ${ }^{58,59}$ The expression of this conserved member of the $\mathrm{BH} 3$ only subfamily of the pro-apoptotic Bcl-2 family proteins correlates with the induction of autophagy in different cell models. ${ }^{60-63}$ Moreover, Bnip3 can dissociate Beclin1 from the Bcl-2-Beclin1 complex, ${ }^{64}$ consistent with our results showing that Bnip3 knockdown affects Beclin1 expression (Figure 6d). Beclin1 is an important component of the class III Ptdlns3K complex, required for the induction of autophagy. Hypoxia preconditioning in hepatocellular carcinoma significant activated autophagy, but this process can be attenuated by Beclin1 knockdown. ${ }^{65}$ In this study, Bnip3 and Beclin1 expression was significantly enhanced in MGCs subjected to hypoxia. Furthermore, Bnip3 or Beclin1 knockdown decreased autophagy signaling in MGCs, suggesting that Bnip3 and Beclin1 regulation is involved in hypoxiainduced autophagy.

During follicular development, the constituent cells, including theca cells, GCs, and oocytes, exhibit a series of functional gene activation. A cohort of follicles that have undergone initial development are stimulated to develop further by rising concentrations of gonadotropins. The GCs become more responsive to $\mathrm{FSH}$ and show a higher rate of proliferation once a follicle is selected as a dominant follicle. Therefore, autophagy appears to be an important, evolutionarily conserved mechanism for maintaining homeostasis and providing energy. ${ }^{66}$ A previous report showed that autophagy was upregulated during cyclic phases of cell proliferation and differentiation. ${ }^{34}$ In addition, Atg3-, Atg5-, or Pik3c3/Vps34deficient $T$ cells cannot efficiently proliferate because of loss of the cell cycle inhibitor, CDKN1B/p27Kip1, which is selectively degraded by autophagy. ${ }^{67}$ In this study, inhibition of autophagy reduced the proliferation rate of MGCs, further decreasing the number of antral follicles and preovulatory follicles.

Once the dominant follicle is mature, GCs begin to express aromatase, to secrete estradiol and increasing the amount of inhibin B. Thus, maintaining the homeostasis of the ovary to produce more mature follicles and prevent follicles from entering atresia is important. Previous results highlighted a critical role for autophagy in the function of GCs. Autophagy inhibition by conditional knockout of Beclin1 in the ovarian GC population causes a defect in progesterone production and a subsequent preterm labor phenotype. ${ }^{68}$ In porcine GC, autophagy activated through NF- $\kappa \mathrm{B}$ inhibition promotes steroidogenesis. ${ }^{46}$ In this study, there was a change in the transcription of progesterone biosynthesis genes, 3 betahydroxysteroid dehydrogenase $(3 \beta-\mathrm{HSD})$ and inhibin alpha subunit $(\mathrm{INH} a)$, representing a crosslink with the molecular regulation of autophagy. Although no change was observed in the levels of CYP19A1, controlling estradiol production, autophagy may still be involved in estradiol signaling, as demonstrated in different cell lines. ${ }^{69-71}$

Reports revealed that autophagy is associated with GC apoptosis and follicle atresia throughout the reproductive period. ${ }^{13,18}$ In this study, although no significant change was observed in apoptosis-related gene expression after autophagy inhibition, the mitochondrial membrane potential was significantly changed through the PINK1-Parkin system, indicating that a selectively autophagy, mitophagy was involved in this process. Since mitophagy facilitates cell death programs, ${ }^{72}$ we speculate that $\mathrm{FSH}$-induced mitophagy has a protective role in damaged mitochondrial clearance. Interestingly, a recent report indicated that defect of mitochondrial fusion protein Mfn2 impaired autophagy-induced degradation, subsequently decreasing mitochondrial oxygen consumption rate and cell glycolysis, reducing ATP production, and suppressing cell proliferation. ${ }^{73}$ Therefore, $\mathrm{FSH}$-induced autophagy is a regulatory mechanism that ensure the order and timing of cell cycle transition by mitophagy activation through the PINK1-Parkin pathway (Figure 8h), which may help reducing follicle atresia and GC apoptosis. ${ }^{74}$

In summary, FSH treatment promotes the activation of autophagy via upregulation of HIF-1 $a$ in MGCs. FSH-mediated autophagy has a protective role on GC proliferation and follicle development through the selective degradation of damaged mitochondria. Blocking FSH-induced autophagy influences steroid production and antral/preovulatory follicle numbers. Overall, our study highlights a mechanism by which FSH regulates MGC autophagy, which may be a novel strategy to reduce follicle atresia and degeneration.

\footnotetext{
Materials and Methods

Animal treatment. All animal experiments were approved by Nanjing Agricultural University, Animal Research Institution Committee. Three to 4-weekold female ICR mice (Nanjing Qinglongshan Experimental Animal Center) were housed, five per cage, in a temperature controlled $\left(22 \pm 2^{\circ} \mathrm{C}\right)$ room with a $12: 12 \mathrm{~h}$ light: dark cycle (lights on from 0700 to 1900 hours) and free access to water and food. To induce MGC autophagy, mice were injected i.p. with FSH (Ningbo Second
}

Figure 7 Blocking autophagy affects mitochondrial membrane potential. (a) Mice treated with or without chloroquine for 5 days were then treated with FSH for 12 h, the expression of LC3 and p62 in MGCs was determined by western blotting. (b) Ovaries derived from mice treat with or without chloroquine and FSH. (c) The effect of autophagy on follicle was quantified by calculating the average ovarian weight. (d) The relative caspase-3 activity after chloroquine and FSH treatment. Detection was performed as described in Materials and Methods section. (e) Mitochondrial membrane potential was measured by JC-1 staining and analyzed by flow cytometry. The upper right fraction was labeled by JC-1 as JC-1 red (intact fraction) and the lower right fraction was labeled by JC-1 as JC-1 green (damaged fraction), respectively. (f) Quantitative analysis of the data in e. (g) The protein expression of PINK1, Parkin, and Tom20 was determined by western blotting. Relative protein levels were normalized to $\alpha$-tubulin. (h) Quantitative analysis of the data in g. The data are means \pm S.E; $(n=3)$. ${ }^{*} P<0.05$. ${ }^{* *} P<0.01$. NS, not significant 
Hormone Factory, Ningbo, China) on four successive occasions (10, 10, 5, and 5 IU) at $12 \mathrm{~h}$ intervals. MGCs were isolated from dominant follicles (DFs; $>200 \mu \mathrm{m}$ ) in the left ovaries of each mouse, for qRT-PCR and immunoblotting. The right ovaries were fixed with $4 \%$ paraformaldehyde and embedded in paraffin for subsequent immunohistology and lysotracker staining. For activator and inhibitor experiments, MHY1485 (10 mg/kg, 2 days) and chloroquine (20 mg/kg, 5 days) obtained from Sigma (St. Louis, MO, USA) were injected before FSH administration. HIF-1 $\alpha$ inhibitor, Px-478, and AMPK inhibitor, compound C, (Selleck Chemicals, Houston, TX, USA) were injected before FSH treatment and the experiment protocol is described in Supplementary Figure S2.

Immunohistology. Mouse ovaries used for histological analysis were fixed with $4 \%$ paraformaldehyde overnight at $4{ }^{\circ} \mathrm{C}$, dehydrated, and embedded in paraffin. Ovarian sections (5- $\mu \mathrm{m}$ thickness) were incubated with anti-LC3 rabbit antibody

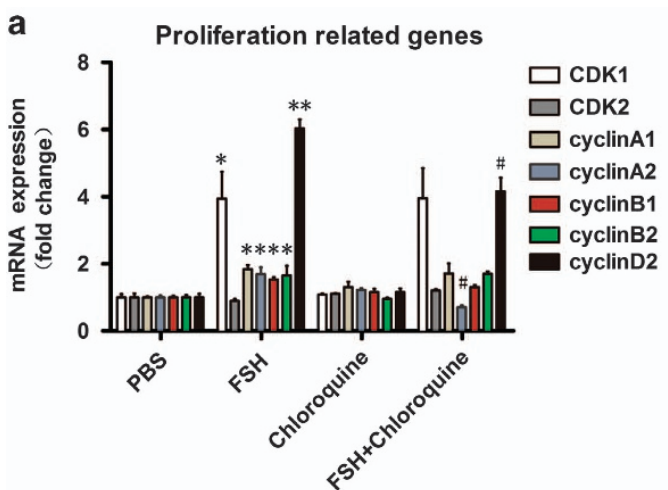

C

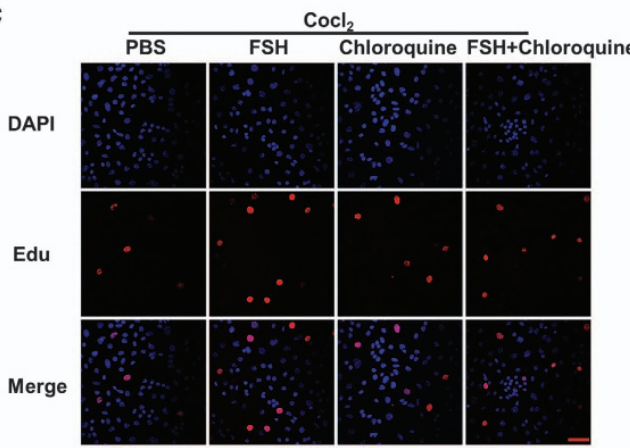

e

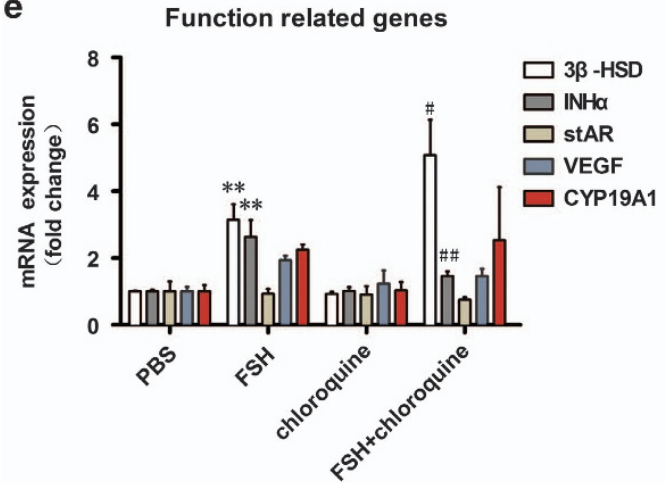

g

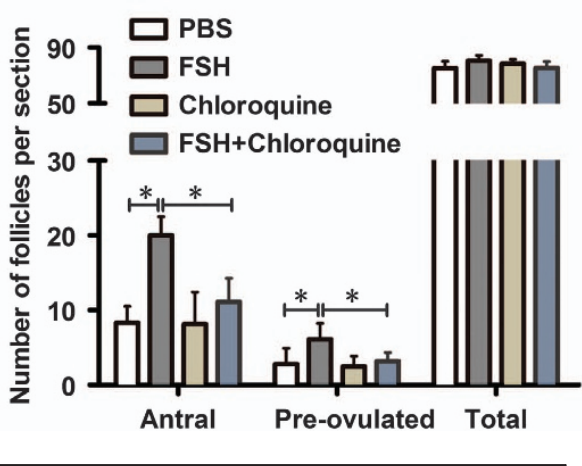

b

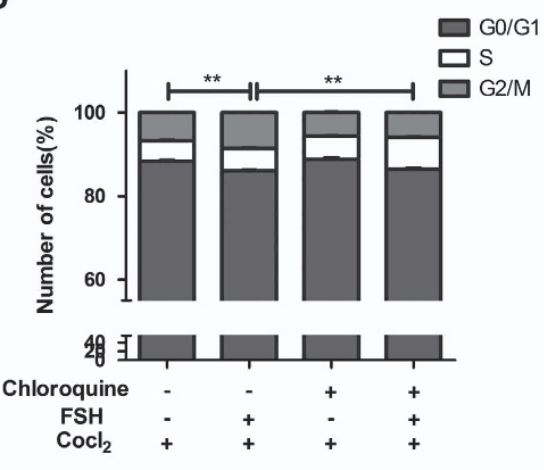

d

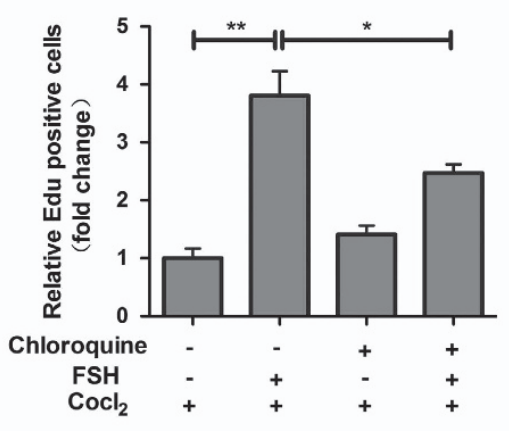

f

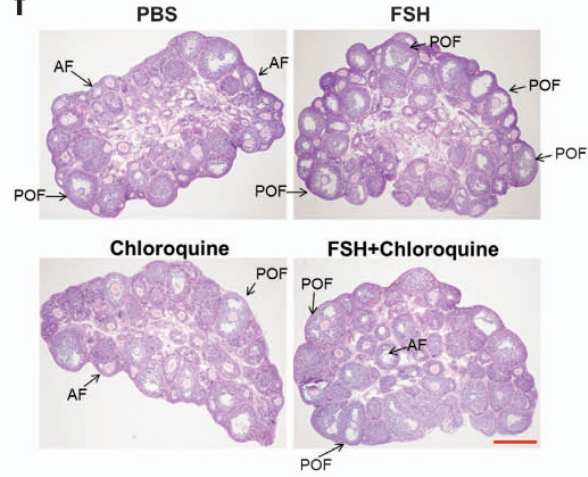

h

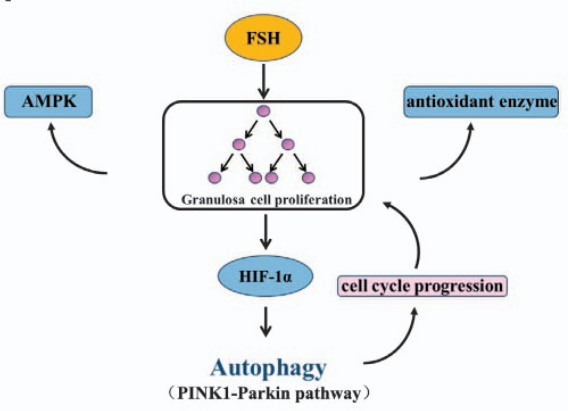


(1:300; \#L8918, Sigma-Aldrich), followed by incubation with a biotinylated secondary antibody (\#B7151, Sigma-Aldrich) for $1 \mathrm{~h}$ at a dilution of 1:500. For lysotracker staining, ovarian sections pretreated as above were incubated for $2 \mathrm{~min}$ with $100 \mu \mathrm{M}$ Lysotracker Red (Beyotime Institute of Biotechnology, Haimen, China) in phosphate-buffered saline (PBS). For H\&E staining, the slides were stained with $\mathrm{H} \& \mathrm{E}$ after deparaffinization. The sections were dehydrated, mounted, and examined using a dotSlide digital virtual microscopy system (Olympus, Tokyo, Japan).

Western blot and antibodies. Cells were harvested by using radioimmune precipitation assay lysis buffer (Pierce Chemical, Rockford, IL, USA) and protein was quantified by the BCA method (Pierce, Chemical). Cell lysates containing $25 \mu \mathrm{g}$ total protein were fractionated by using SDS-PAGE and transferred onto PVDF membranes (Millipore, Billerica, MA, USA). After blocking with 5\% BSA in Trisbuffered saline containing Tween (TBST) for $1 \mathrm{~h}$, membranes were incubated with primary antibody in TBST overnight at $4{ }^{\circ} \mathrm{C}$. The antibodies, LC3 (1:1000; \#L8918) was from Sigma-Aldrich, p62 (1:1000; \#5114), AMPK (1:1000; \#5832), AMPK (phosphor-Thr172) (1:1000; \#2535), Bnip3 (1:1000; \#3769), p70S6K (1:1000; \#2708), p70S6K (phosphor-Thr389) (1:1000; \#9206), and Parkin (1:1000; \#2132) were purchased from Cell Signaling Technology (Danvers, MA, USA). Anti-AKT (1:1000; \#ab18785), anti-AKT (phospho-ser473) (1:1000; \#ab66138), anti-mTOR (1:1000; \#ab2732), anti-mTOR (phospho-ser2448) (1:1000; \#ab1093), anti-HIF-1 $\alpha$ (1:1000; \#ab179483), anti-PINK (1:1000; \#ab23707) were obtained from Abcam (Cambridge, UK). Anti-Beclin1 (1:500; \#sc-11427) and anti-Tom20 (1:500; \#SC-11021) were from Santa Cruz Biotechnology (Santa Cruz, CA, USA). Subsequently, the membrane was incubated in HRP-conjugated anti-rabbit secondary antibody (1:2000; \#7074, Cell Signaling Technology) or anti-mouse secondary antibody (1:2000; \#7076, Cell Signaling Technology) for $2 \mathrm{~h}$ at room temperature. After washing, the membrane was processed by using SuperSignal West Pico chemiluminescent substrate (Pierce Chemical). As an internal control, $\alpha$ tubulin was detected by using an anti-tubulin antibody (1:2000; \#T5168, SigmaAldrich).

Quantitative RT-PCR (qRT-PCR). Total RNA was extracted by using TRIZOL (Invitrogen, Carlsbad, CA, USA) and reverse-transcribed into cDNA using Moloney murine leukemia virus RT according to the manufacturer's protocol (Bio-Rad, Hercules, CA, USA). Real-time PCR was performed with SYBR Premix Ex Taq (Takara Bio, Tokyo, Japan) in a reaction volume of $20 \mu \mathrm{l}$ and the $\mathrm{ABI}$ StepOne system (Applied Biosystems, Foster City, CA, USA). Primer sequences are listed in Appendix: Supplementary Table S1. Melting curves were analyzed to verify amplification specificity. Expression data were normalized to the amount of GAPDH expressed.

Cell proliferation assay. The proliferation of MGCs was determined by using a Cell Counting Kit-8 (CCK-8) (Dojindo Laboratories, Japan) and a 5-ethynyl-2'deoxyuridine (EdU) assay using an EdU assay kit (Ribobio, Guangzhou, China) according to the manufacturer's protocol. In brief, cells were plated into 96-well plates at a concentration of $5 \times 10^{3}$ cells/well. After treatment as indicated, cells were collected and seeded into a 96-well plate. CCK-8 solution ( $10 \mu \mathrm{l}$ ) was added to each well, followed by incubation for $2 \mathrm{~h}$ at $37^{\circ} \mathrm{C}$. The absorbance at $450 \mathrm{~nm}$ was determined by using a multiplate reader (Lambda Bio-20; Beckman, La Brea, CA, USA). The cell viability was calculated by the optical density (OD) values of treated groups/OD values of control group $\times 100 \%$. For the EdU assay, $25 \mu \mathrm{M}$ EdU was added to the cells, and the cells were incubated for $2 \mathrm{~h}$ at $37^{\circ} \mathrm{C}$. The cells were then fixed with $4 \%$ paraformaldehyde for $15 \mathrm{~min}$ at room temperature and exposed to $0.5 \%$ Triton X-100 for 20 min. After 3 washes with PBS, the cells were stained with $100 \mu \mathrm{l}$ of Apollo Dye Solution for $30 \mathrm{~min}$. The nucleic acids in all of the cells were stained with DAPI. Images were taken by using a fluorescence microscope (Carl Zeiss, Germany). All experiments were performed in triplicate.

Intracellular ROS measurement. Following FSH treatment, follicular GCs were collected by puncture of the dominant ovarian follicle $(>200 \mathrm{~mm})$ in the ovary. Levels of ROS in cells were measured by using the GENMED cellular superoxide anion colorimetric quantitative determination kit (GENMED, Shanghai, China). All procedures were performed according to the manufacturer's instructions.

AMPK activity assay. After FSH treatment, cells were harvested and the AMPK activity was measured at an absorbance of $595 \mathrm{~nm}$ according to the manufacturer's protocol (GENMED, Shanghai, China). The AMPK experiments were conducted in triplicate, and the results were normalized to cell protein concentration.

MGC culture. Mice were injected intraperitoneally with 10 units of PMSG ${ }^{75}$ and euthanized $44 \mathrm{~h}$ later. Superovulated mouse ovaries were obtained and transferred to petri dishes $(35 \times 15 \mathrm{~mm})$ filled with PBS, then punctured with a syringe to release MGCs from DFs ( $>200 \mu \mathrm{m}$ in diameter) under a surgical dissecting microscope. MGCs $\left(1 \times 10^{6}\right)$ were plated into T25 flasks in $4 \mathrm{ml}$ of Dulbecco's Modified Eagle's Medium: Nutrient Mixture F-12 (1:1; Life Technologies, Carlsbad, CA, USA) supplemented with $15 \%$ fetal bovine serum (Life Technologies) and $1 \%$ antibiotics (100 IU/ml penicillin and $100 \mu \mathrm{g} / \mathrm{ml}$ streptomycin; Life Technologies). To induce cell hypoxia, $200 \mu \mathrm{M} \mathrm{CoCl}$ (Sigma-Aldrich) was added to the culture medium at a concentration of $150 \mu \mathrm{M}$. Induced cells were harvested for different assays.

Cell transfection. HIF-1 $\alpha$ siRNA, Beclin1 siRNA, and Bnip3 siRNA were purchased from Santa Cruz Biotechnology (\#sc-35562; \#sc-29798; and \#sc-37452). GFP-LC3 plasmid was kindly provided by Jiyong Zhou of Zhejiang University, Zhejiang, China. Transfections were performed by using Lipofectamine 2000 (Invitrogen) following the manufacturer's instructions. The medium was replaced $5 \mathrm{~h}$ after transfection.

GFP-LC3 assay. MGCs were seeded into 24-well plates post-treatment, the coverslips were washed, mounted on slides, and inspected under a confocal laser scanning microscope (Carl Zeiss, Göttingen, Germany). Several bright green fluorescent puncta were observed in the cells. One punctum was considered equal to one autophagosome. The results are presented as the average number of puncta per cell.

Caspase- 3 activity assay. The activity of caspase- 3 was determined by using the Caspase-3 activity kit (Beyotime Institute of Biotechnology) according to the manufacturer's instructions. After treatment, GCs were homogenized in $100 \mathrm{ml}$ reaction buffer (1\% NP-40, $20 \mathrm{mM}$ Tris- $\mathrm{HCl}(\mathrm{pH} 7.5), 137 \mathrm{mM} \mathrm{Nad}$, and $10 \%$ glycerol) containing $10 \mathrm{~mL}$ caspase-3 substrate (Ac-DEV D-pNA) (2 mM). Lysates were incubated at $37^{\circ} \mathrm{C}$ for $2 \mathrm{~h}$. Samples were measured with a microplate reader at an absorbance of $405 \mathrm{~nm}$.

JC-1 assay. The lipophilic cation JC-1 was used to assess the mitochondrial status of MGC. According to the manufacturer (Beyotime Institute of Biotechnology), JC-1 reversibly changes its fluorescence from green (monomeric status) to orange (multimeric status) when the mitochondrial membrane potential is high.

After treatment, $1 \times 10^{6}$ cells of each group were collected and incubated with $10 \mu \mathrm{g} / \mathrm{ml}$ of $5,5^{\prime}, 6,6^{\prime}$-tetrachloro-1, $1^{\prime}, 3,3^{\prime}$-tetraethylimidacarbocyanine iodide (JC-1) at $37^{\circ} \mathrm{C}, 5 \% \mathrm{CO} 2$ for $30 \mathrm{~min}$. The cells were analyzed by using a BD FACScan system (Becton Dickinson, Franklin, NJ, USA).

Figure 8 FSH-induced autophagy promotes MGC proliferation. (a) Mice treated with or without chloroquine for 5 days were then treated with FSH for $12 \mathrm{~h}$, the proliferation related genes were determined by qPCR. The relative expression data were normalized to the amount of GAPDH. Significances were marked as ${ }^{*} P<0.05$. ${ }^{*} P<0.01$ versus PBS group; ${ }^{\#} P<0.05$ versus FSH group. (b) Analysis of cell proliferation. Cells treated with $\mathrm{Cocl}_{2}$ and $\mathrm{FSH}$ were incubated with chloroquine at $24 \mathrm{~h}$ before the detection. The cell cycle profile was analyzed by flow cytometry using Propidium lodide (PI). (c) MGCs treated as described in b were labeled with EdU, EdU-positive cells, red; cell nuclei, blue; Bar $=50 \mu \mathrm{m}$. (d) Quantitative analysis of the data in c. (e) The function related genes were determined by qPCR. GAPDH was used as an internal control. Significances were marked as ${ }^{* *} P<0.01$ versus PBS group; ${ }^{\#} P<0.05$. ${ }^{\# \#} P<0.01$ versus FSH group. (f) Representative H\&E staining of ovaries. Bar $=500 \mu$ m. $A F$, antral follicle; $P O F$, pre-ovulated follicle. (g) Quantitative analysis of the data in (f). The data are means \pm S.E; $(n=3)$. ${ }^{*} P<0.05$. ${ }^{* *} P<0.01$. (h) Schematic representation of FSH regulation of autophagy in MGC. FSH-mediated cell proliferation promotes HIF-1 $\alpha$ expression, which further leads to autophagy in hypoxic condition. Autophagy transfers the hypoxic stress through the mitophagy pathway and participates in the regulation of the cell cycle, which has a positive feedback on cell proliferation 
Cell cycle assay. Cells were harvested, centrifuged at 12000 r.p.m. for 5 min, and washed three times with cold PBS. Subsequently, the cells were fixed in $70 \%$ ice cold ethanol overnight at $4{ }^{\circ} \mathrm{C}$. After 30 min digestion with $1 \mu \mathrm{g} / \mu$ l RNase, the cells were resuspended in $250 \mu$ l of propidium iodide staining solution $(10 \mu \mathrm{g} / \mathrm{ml})$ and incubated for $1 \mathrm{~h}$ at room temperature in the dark. The distribution of cells in the G0/G1, S, and G2/M phase was determined following analysis on a BD FACScan system (Becton Dickinson).

Follicle classification and counting. Ovaries were cut into $3-5 \mathrm{~mm}$-thick sections, deparaffinized, hydrated through ethanol series, and stained with $\mathrm{H} \& \mathrm{E}$. Ovarian follicles at different developmental stages were counted in collected sections of an ovary, based on the well-accepted standards established by Pedersen and Peters. ${ }^{76}$ In brief, follicles were classified as antral follicles when antrum formation was visible. Follicles presenting a rim of cumulus cells surrounding the oocyte were classified as preovulatory follicles.

Statistical analysis. Data were analyzed by using SPSS version 18.0 (SPSS Inc., Chicago, IL, USA). Statistical significance was calculated with the Student's $t$-test $(P<0.05$ was considered statistically significant). All experiments were repeated at least three times. Results are expressed as the mean \pm S.E.

\section{Conflict of Interest}

The authors declare no conflict of interest.

Acknowledgements. This work was supported by the National Natural Science Foundation of China (31472073), the 973 Program (2014CB138502), the State Key Program of National Natural Science Foundation of China (31630072), and the National Natural Science Foundation of China (31501920).

\section{Author contributions}

$J Z$ conceived and designed the experiments. JZ and WY carried out the experiments. $J Z$ analyzed the data and drafted the manuscript. CL, WW, and QL revised the manuscript. $\mathrm{HL}$ supervised the research. All the authors have read and approved the final manuscript.

\section{Publisher's Note}

Springer Nature remains neutral with regard to jurisdictional claims in published maps and institutional affiliations.

1. Xie Z, Klionsky DJ. Autophagosome formation: core machinery and adaptations. Nat Cell Biol 2007; 9: 1102-1109.

2. Mizushima N. Autophagy: process and function. Genes Dev 2007; 21: 2861-2873.

3. Sato K, Tsuchihara K, Fujii S, Sugiyama M, Goya T, Atomi Y et al. Autophagy is activated in colorectal cancer cells and contributes to the tolerance to nutrient deprivation. Cancer Res 2007; 67: 9677-9684.

4. Azad MB, Chen Y, Henson ES, Cizeau J, McMillan-Ward E, Israels SJ et al. Hypoxia induces autophagic cell death in apoptosis-competent cells through a mechanism involving BNIP3. Autophagy 2008; 4: 195-204

5. Lum JJ, Bauer DE, Kong M, Harris MH, Li C, Lindsten T et al. Growth factor regulation of autophagy and cell survival in the absence of apoptosis. Cell 2005; 120: 237-248.

6. Maiuri MC, Zalckvar E, Kimchi A, Kroemer G. Self-eating and self-killing: crosstalk between autophagy and apoptosis. Nat Rev Mol Cell Biol 2007; 8: 741-752.

7. Rabinowitz JD, White E. Autophagy and metabolism. Science 2010; 330: 1344-1348.

8. Deretic V. Autophagy in immunity and cell-autonomous defense against intracellular microbes. Immunol Rev 2011; 240: 92-104.

9. Levine B, Kroemer G. Autophagy in the pathogenesis of disease. Cell 2008; 132: 27-42.

10. Matsuda F, Inoue N, Manabe N, Ohkura S. Follicular growth and atresia in mammalian ovaries: regulation by survival and death of granulosa cells. J Reprod Dev 2012; 58: 44-50.

11. Yu YS, Sui HS, Han ZB, Li W, Luo MJ, Tan JH. Apoptosis in granulosa cells during follicular atresia: relationship with steroids and insulin-like growth factors. Cell Res 2004; 14:341-346.

12. D'Herde K, De Prest B, Roels F. Subtypes of active cell death in the granulosa of ovarian atretic follicles in the quail (Coturnix coturnix japonica). Reprod Nutr Dev 1996; 36: 175-189.

13. Choi JY, Jo MW, Lee EY, Yoon BK, Choi DS. The role of autophagy in follicular development and atresia in rat granulosa cells. Fertility Sterility 2010; 93: 2532-2537.

14. Choi J, Jo M, Lee E, Choi D. Induction of apoptotic cell death via accumulation of autophagosomes in rat granulosa cells. Fertility Sterility 2011; 95: 1482-1486.

15. Wu J, Carlock C, Zhou C, Nakae S, Hicks J, Adams HP et al. IL-33 is required for disposal of unnecessary cells during ovarian atresia through regulation of autophagy and macrophage migration. J Immunol 2015; 194: 2140-2147.
16. Song ZH, Yu HY, Wang P, Mao GK, Liu WX, Li MN et al. Germ cell-specific Atg7 knockout results in primary ovarian insufficiency in female mice. Cell Death Dis 2015; 6: e1589.

17. Gawriluk TR, Hale AN, Flaws JA, Dillon CP, Green DR, Rucker EB 3rd. Autophagy is a cell survival program for female germ cells in the murine ovary. Reproduction 2011; 141 : 759-765.

18. Hulas-Stasiak M, Gawron A. Follicular atresia in the prepubertal spiny mouse (Acomys cahirinus) ovary. Apoptosis 2011; 16: 967-975.

19. Peluso JJ, Steger RW. Role of FSH in regulating granulosa cell division and follicular atresia in rats. J Reprod Fertil 1978; 54: 275-278.

20. Chun SY, Eisenhauer KM, Minami S, Billig H, Perlas E, Hsueh AJ. Hormonal regulation of apoptosis in early antral follicles: follicle-stimulating hormone as a major survival factor. Endocrinology 1996; 137: 1447-1456.

21. Choi J, Jo M, Lee E, Choi D. AKT is involved in granulosa cell autophagy regulation via mTOR signaling during rat follicular development and atresia. Reproduction 2014; 147: 73-80.

22. Yamashita $Y$, Hishinuma M, Shimada M. Activation of PKA, p38 MAPK and ERK1/2 by gonadotropins in cumulus cells is critical for induction of EGF-like factor and TACE/ ADAM17 gene expression during in vitro maturation of porcine COCs. J Ovarian Res 2009; 2: 20.

23. Codogno P, Meijer AJ. Autophagy and signaling: their role in cell survival and cell death. Cell Death Differ 2005; 12: 1509-1518.

24. Kumar TR, Wang Y, Lu N, Matzuk MM. Follicle stimulating hormone is required for ovarian follicle maturation but not male fertility. Nat Genet 1997; 15: 201-204.

25. Durlinger AL, Gruijters MJ, Kramer P, Karels B, Kumar TR, Matzuk MM et al. Anti-Mullerian hormone attenuates the effects of FSH on follicle development in the mouse ovary. Endocrinology 2001; 142: 4891-4899.

26. Vander Heiden MG, Plas DR, Rathmell JC, Fox CJ, Harris MH, Thompson CB. Growth factors can influence cell growth and survival through effects on glucose metabolism. Mol Cell Biol 2001; 21: 5899-5912.

27. Bodet L, Menoret E, Descamps G, Pellat-Deceunynck C, Bataille R, Le Gouill S et al. $\mathrm{BH}$-only protein Bik is involved in both apoptosis induction and sensitivity to oxidative stress in multiple myeloma. Br J Cancer 2010; 103: 1808-1814.

28. Wang X, Zhang J, Fu J, Wang J, Ye S, Liu W et al. Role of ROS-mediated autophagy in radiation-induced bystander effect of hepatoma cells. Int J Radiat Biol 2015; 91: 452-458.

29. Bruick RK. Expression of the gene encoding the proapoptotic Nip3 protein is induced by hypoxia. Proc Natl Acad Sci USA 2000; 97: 9082-9087.

30. Zhang J, Ney PA. Role of BNIP3 and NIX in cell death, autophagy, and mitophagy. Cell Death Differ 2009; 16: 939-946.

31. Nikoletopoulou V, Markaki M, Palikaras K, Tavernarakis N. Crosstalk between apoptosis, necrosis and autophagy. Biochim Biophys Acta 2013; 1833: 3448-3459.

32. Khosravi-Far R, Esposti MD. Death receptor signals to mitochondria. Cancer Biol Ther 2004; 3: 1051-1057.

33. Narendra D, Tanaka A, Suen DF, Youle RJ. Parkin is recruited selectively to impaired mitochondria and promotes their autophagy. J Cell Biol 2008; 183: 795-803.

34. Gaytan M, Morales C, Sanchez-Criado JE, Gaytan F. Immunolocalization of beclin 1, a bcl-2binding, autophagy-related protein, in the human ovary: possible relation to life span of corpus luteum. Cell Tissue Res 2008; 331: 509-517.

35. Serke H, Vilser C, Nowicki M, Hmeidan FA, Blumenauer V, Hummitzsch K et al. Granulosa cell subtypes respond by autophagy or cell death to oxLDL-dependent activation of the oxidized lipoprotein receptor 1 and toll-like 4 receptor. Autophagy 2009; 5: 991-1003.

36. Yu J, Lou Y, He K, Yang S, Yu W, Han L et al. Goose broodiness is involved in granulosa cell autophagy and homeostatic imbalance of follicular hormones. Poult Sci 2016; 95 : $1156-1164$.

37. Vilser C, Hueller H, Nowicki M, Hmeidan FA, Blumenauer V, Spanel-Borowski K. The variable expression of lectin-like oxidized low-density lipoprotein receptor (LOX-1) and signs of autophagy and apoptosis in freshly harvested human granulosa cells depend on gonadotropin dose, age, and body weight. Fertility Sterility 2010; 93: 2706-2715.

38. Jiang JY, Cheung CK, Wang Y, Tsang BK. Regulation of cell death and cell survival gene expression during ovarian follicular development and atresia. Front Biosci 2003; 8: d222-d237.

39. Hunzicker-Dunn M, Maizels ET. FSH signaling pathways in immature granulosa cells that regulate target gene expression: branching out from protein kinase A. Cell Signal 2006; 18: 1351-1359.

40. Akabane S, Uno M, Tani N, Shimazaki S, Ebara N, Kato H et al. PKA regulates PINK1 stability and parkin recruitment to damaged mitochondria through phosphorylation of MIC60. Mol Cell 2016; 62: 371-384.

41. Zhou J, Yao W, Liu K, Wen Q, Wu W, Liu $\mathrm{H}$ et al. MicroRNA let-7 g regulates mouse granulosa cell autophagy by targeting insulin-like growth factor 1 receptor. Int $J$ Biochem Cell Biol 2016; 78: 130-140.

42. Basu S, Rajakaruna S, Reyes B, Van Bockstaele E, Menko AS. Suppression of MAPK/JNKMTORC1 signaling leads to premature loss of organelles and nuclei by autophagy during terminal differentiation of lens fiber cells. Autophagy 2014; 10: 1193-1211.

43. Anand PK, Tait SW, Lamkanfi M, Amer AO, Nunez G, Pages G et al. TLR2 and RIP2 pathways mediate autophagy of Listeria monocytogenes via extracellular signal-regulated kinase (ERK) activation. J Biol Chem 2011; 286: 42981-42991.

44. Gueripel X, Benahmed M, Gougeon A. Sequential gonadotropin treatment of immature mice leads to amplification of transforming growth factor beta action, via upregulation of 
receptor-type 1, Smad 2 and 4, and downregulation of Smad 6. Biol Reprod 2004; 70: 640-648.

45. Zhang D, Li J, Xu G, Zhang R, Zhou C, Qian Y et al. Follicle-stimulating hormone promotes age-related endometrial atrophy through cross-talk with transforming growth factor beta signal transduction pathway. Aging Cell 2015; 14: 284-287.

46. Gao H, Lin L, Haq IU, Zeng SM. Inhibition of NF-kappaB promotes autophagy via JNK signaling pathway in porcine granulosa cells. Biochem Biophys Res Commun 2016; 473: 311-316.

47. Klionsky DJ, Abdalla FC, Abeliovich H, Abraham RT, Acevedo-Arozena A, Adeli K et al. Guidelines for the use and interpretation of assays for monitoring autophagy. Autophagy 2012; 8: 445-544.

48. Dennis PB, Fumagalli S, Thomas G. Target of rapamycin (TOR): balancing the opposing forces of protein synthesis and degradation. Curr Opin Genet Dev 1999; 9: 49-54.

49. Semenza GL. HIF-1 and tumor progression: pathophysiology and therapeutics. Trends $\mathrm{Mol}$ Med 2002; 8: S62-S67.

50. Krishnamachary B, Berg-Dixon S, Kelly B, Agani F, Feldser D, Ferreira G et al. Regulation of colon carcinoma cell invasion by hypoxia-inducible factor 1. Cancer Res 2003; 63: 1138-1143.

51. Seagroves TN, Ryan HE, Lu H, Wouters BG, Knapp M, Thibault P et al. Transcription factor $\mathrm{HIF-1}$ is a necessary mediator of the pasteur effect in mammalian cells. Mol Cell Biol 2001; 21: $3436-3444$

52. Tacchini L, Bianchi L, Bernelli-Zazzera A, Cairo G. Transferrin receptor induction by hypoxia HIF-1-mediated transcriptional activation and cell-specific post-transcriptional regulation. J Biol Chem 1999; 274: 24142-24146.

53. Huang Y, Hua K, Zhou X, Jin H, Chen X, Lu X et al. Activation of the PI3K/AKT pathway mediates FSH-stimulated VEGF expression in ovarian serous cystadenocarcinoma. Cell Res 2008; 18: 780-791.

54. Alam H, Weck J, Maizels E, Park Y, Lee EJ, Ashcroft M et al. Role of the phosphatidylinositol3-kinase and extracellular regulated kinase pathways in the induction of hypoxia-inducible factor (HIF)-1 activity and the HIF-1 target vascular endothelial growth factor in ovarian granulosa cells in response to follicle-stimulating hormone. Endocrinology 2009; 150: 915-928.

55. Alam H, Maizels ET, Park Y, Ghaey S, Feiger ZJ, Chandel NS et al. Follicle-stimulating hormone activation of hypoxia-inducible factor-1 by the phosphatidylinositol 3-kinase/AKT/ Ras homolog enriched in brain (Rheb)/mammalian target of rapamycin (mTOR) pathway is necessary for induction of select protein markers of follicular differentiation. $\mathrm{J}$ Biol Chem 2004; 279: 19431-19440.

56. Mazure NM, Pouyssegur J. Hypoxia-induced autophagy: cell death or cell survival? Curr Opin Cell Biol 2010; 22: 177-180.

57. Kroemer G, Marino G, Levine B. Autophagy and the integrated stress response. Mol Cell 2010; 40: 280-293.

58. Zhang H, Bosch-Marce M, Shimoda LA, Tan YS, Baek JH, Wesley JB et al. Mitochondrial autophagy is an HIF-1-dependent adaptive metabolic response to hypoxia. $\mathrm{J}$ Biol Chem 2008; 283: 10892-10903.

59. Zhao Y, Chen G, Zhang W, Xu N, Zhu JY, Jia J et al. Autophagy regulates hypoxia-induced osteoclastogenesis through the HIF-1alpha/BNIP3 signaling pathway. J Cell Physiol 2012; 227: 639-648.

60. Daido S, Kanzawa T, Yamamoto A, Takeuchi H, Kondo Y, Kondo S. Pivotal role of the cell death factor BNIP3 in ceramide-induced autophagic cell death in malignant glioma cells. Cancer Res 2004; 64: 4286-4293.

61. Lee Y, Lee HY, Hanna RA, Gustafsson AB. Mitochondrial autophagy by Bnip3 involves Drp1mediated mitochondrial fission and recruitment of Parkin in cardiac myocytes. Am J Physiol Heart Circ Physiol 2011; 301: H1924-H1931.

62. Hamacher-Brady A, Brady NR, Logue SE, Sayen MR, Jinno M, Kirshenbaum LA et al. Response to myocardial ischemia/reperfusion injury involves Bnip3 and autophagy. Cell Death Differ 2007; 14: 146-157.
63. Bellot G, Garcia-Medina R, Gounon P, Chiche J, Roux D, Pouyssegur J et al. Hypoxiainduced autophagy is mediated through hypoxia-inducible factor induction of BNIP3 and BNIP3L via their BH3 domains. Mol Cell Biol 2009; 29: 2570-2581.

64. Maiuri MC, Le Toumelin G, Criollo A, Rain JC, Gautier F, Juin P et al. Functional and physical interaction between $\mathrm{Bcl}-\mathrm{X}(\mathrm{L})$ and a BH3-like domain in Beclin-1. EMBO J 2007; 26 : 2527-2539.

65. Song J, Guo X, Xie X, Zhao X, Li D, Deng W et al. Autophagy in hypoxia protects cancer cells against apoptosis induced by nutrient deprivation through a Beclin1-dependent way in hepatocellular carcinoma. J Cell Biochem 2011; 112: 3406-3420.

66. Ryter SW, Cloonan SM, Choi AM. Autophagy: a critical regulator of cellular metabolism and homeostasis. Mol Cells 2013; 36: 7-16.

67. Jia W, He MX, McLeod IX, Guo J, Ji D, He YW. Autophagy regulates T lymphocyte proliferation through selective degradation of the cell-cycle inhibitor CDKN1B/p27Kip1. Autophagy 2015; 11: 2335-2345.

68. Gawriluk TR, Ko C, Hong X, Christenson LK, Rucker EB 3rd. Beclin-1 deficiency in the murine ovary results in the reduction of progesterone production to promote preterm labor. Proc Natl Acad Sci USA 2014; 111: E4194-E4203.

69. Wolmarans E, Mqoco TV, Stander A, Nkandeu SD, Sippel K, McKenna R et al. Novel estradiol analogue induces apoptosis and autophagy in esophageal carcinoma cells. Cell Mol Biol Lett 2014; 19: 98-115.

70. Yang YH, Chen K, Li B, Chen JW, Zheng XF, Wang YR et al. Estradiol inhibits osteoblas apoptosis via promotion of autophagy through the ER-ERK-mTOR pathway. Apoptosis 2013; 18: $1363-1375$.

71. Zielniok K, Motyl T, Gajewska M. Functional interactions between 17 beta -estradiol and progesterone regulate autophagy during acini formation by bovine mammary epithelial cells in 3D cultures. Biomed Res Int 2014; 2014: 382653.

72. Sentelle RD, Senkal CE, Jiang W, Ponnusamy S, Gencer S, Selvam SP et al. Ceramide targets autophagosomes to mitochondria and induces lethal mitophagy. Nature Chem Biol 2012; 8: 831-838.

73. Ding Y, Gao H, Zhao L, Wang X, Zheng M. Mitofusin 2-deficiency suppresses cell proliferation through disturbance of autophagy. PLOS ONE 2015; 10: e0121328.

74. Quirk SM, Cowan RG, Harman RM, Hu CL, Porter DA. Ovarian follicular growth and atresia: the relationship between cell proliferation and survival. J Anim Sci 2004; 82 E40-E52

75. Nicolson GL, Yanagimachi R, Yanagimachi H. Ultrastructural localization of lectin-binding sites on the zonae pellucidae and plasma membranes of mammalian eggs. J Cell Biol 1975 66: 263-274.

76. Pedersen $T$, Peters $H$. Proposal for a classification of oocytes and follicles in the mouse ovary. J Reprod Fertil 1968; 17: 555-557.

(i) Cell Death and Disease is an open-access journa published by Nature Publishing Group. This work is licensed under a Creative Commons Attribution 4.0 International License. The images or other third party material in this article are included in the article's Creative Commons license, unless indicated otherwise in the credit line; if the material is not included under the Creative Commons license, users will need to obtain permission from the license holder to reproduce the material. To view a copy of this license, visit http://creativecommons.org/licenses/by/4.0/

(C) The Author(s) 2017

Supplementary Information accompanies this paper on Cell Death and Disease website (http://www.nature.com/cddis). 